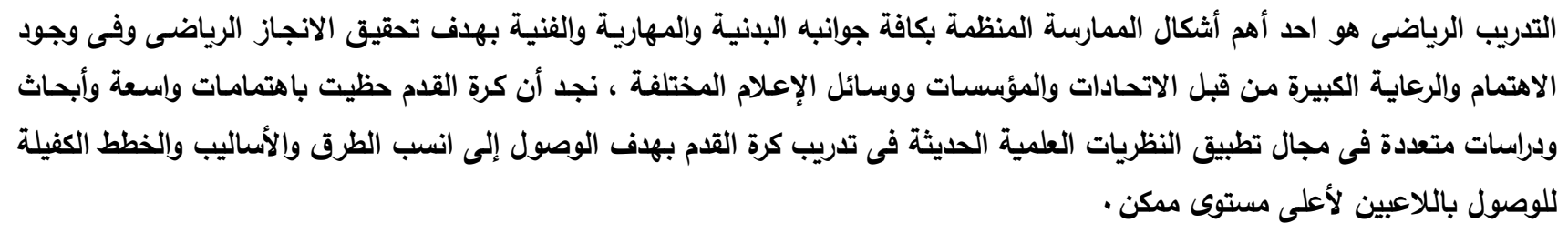

Effect of two methods of training to the development of some special physical qualities and skills combined offensive to football players

\title{
Abstract in English
}

sports training is one of the most important forms of practice in all its aspects and physical skill and artistic to athletic accomplishment and a great attention and care by associations, institutions and the media, football gained a wide interest and research in the application of modern scientific theories on football training to reach the most suitable ways and methods and plans to bring the players to the highest possible level .

Since the aim of physical training to prepare the player numbers and that breach any aspects of training is considered a breach of the training situation as a whole and this reflects the importance of preparing the integrated players, through follow-up to the training was we must provide better and better to improve football training and access to players llformh, since the training method and his method is different in football as the training period, whether a private or public setting or prepare for matches (Before competitions) or transition so the training method in each period different from the period .

With the sophistication in the level of football and that has recently characterized by power and speed performance was to be the study of training methods to determine the best and most appropriate after deteriorating level Egyptian football so we tried to use two methods of their reliance on strength training, speed and impact on motor vehicle and multiple performances throughout the time of the game that determine the efficiency of the player which is also a scientific basis for the selection of players or move between international and local clubs, as well as the development of training programmes and their impact on The level of technical performance of the players, and have been using two of the most recent training methods (simultaneous training-training differential) to choose the most suitable one depending on the search variables using two experimental (program group) the main results that the two had a positive impact for the benefit of remote measurements but the improvement of the experimental group first used simultaneous training method is greater than the second experimental group used disparate training so we recommend that you use these programs on training football And other games. 


\section{" تأثير إسلوبى تدريب على تنهية بعض الصفات البدنية الخاصة والمهارات المندهجة الهجوهية

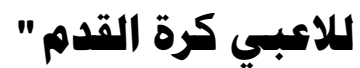

\section{* د أحمد إبراهيم إبراهيم شلغم}

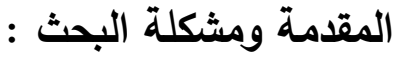

كرة القدم من الأنثطة الرياضية ذات الثعبية العالية على مستوى العالم لكثرة وتعدد وتنوع مهاراتها ،

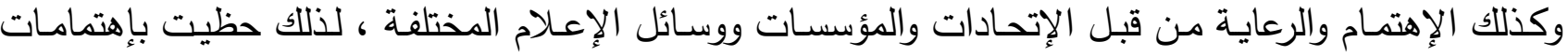

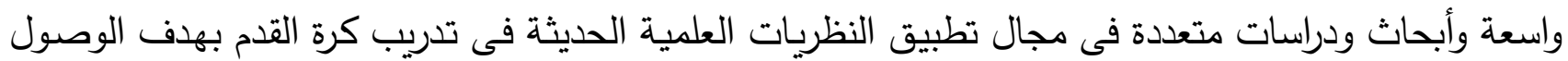
إلى أنسب الطرق والأساليب والخطط الكفيلة للوصول باللاعبين لأعلى مستوى ممكن .

ويهذف التدريب الرياضى إلى إعداد اللاعب إعداداً متكاملاً والتأكيد حيث أن الإخلال بأي جانب من العند

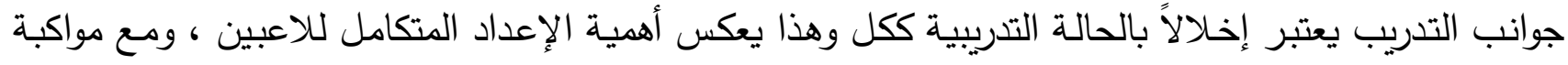

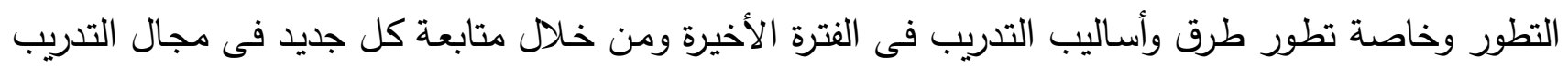

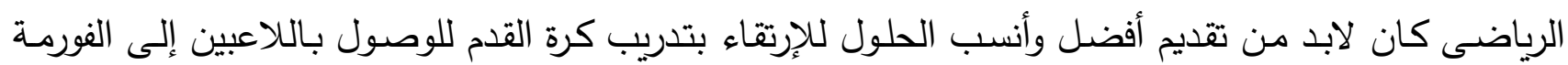
الرياضية.

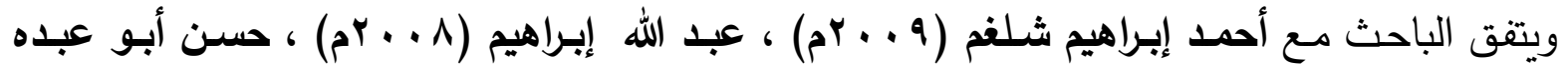

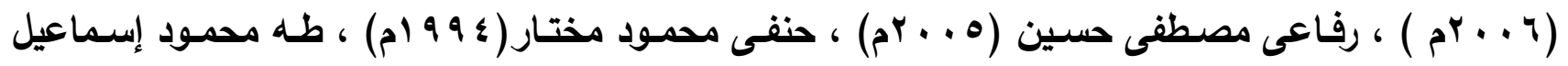

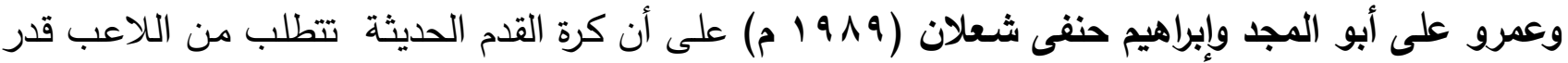

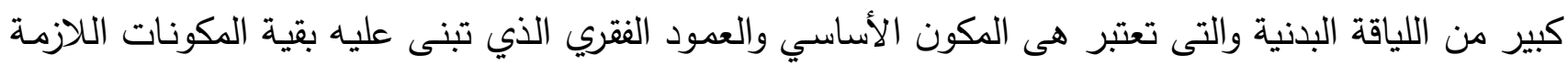

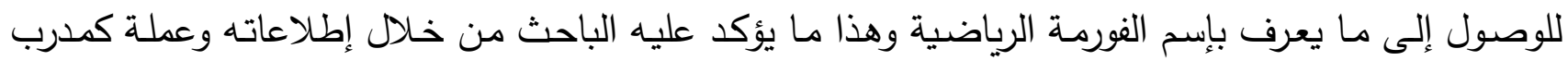

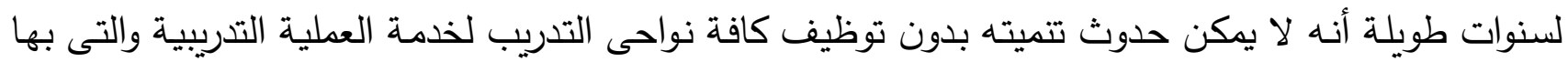

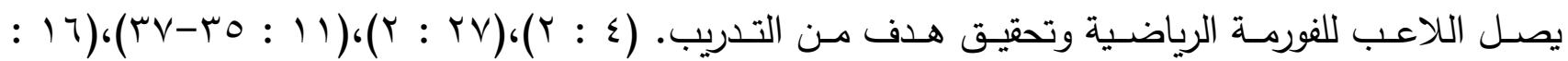

$$
\text { . (r): rT) (T): }:(r) \cdot(r r
$$

كما تكمن أهمية البحث فى أن القدرات البدنية الخاصة في كرة القدم تثكل الأسساس فى رفع مستوى

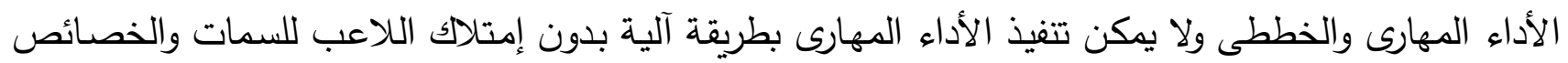

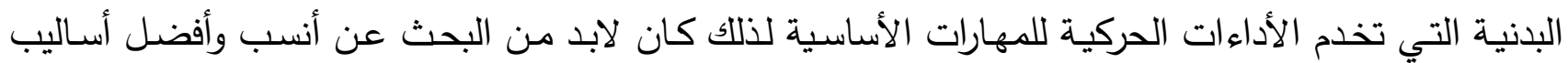

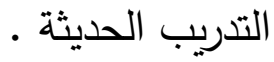

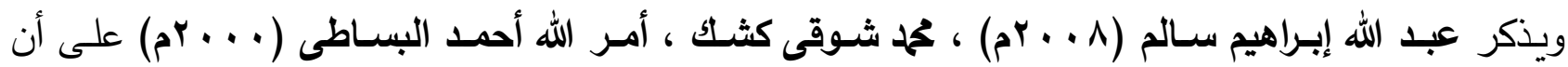

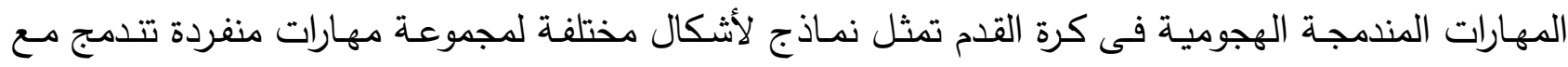

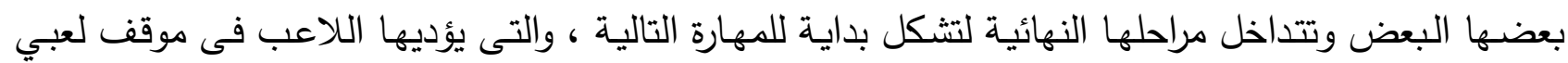

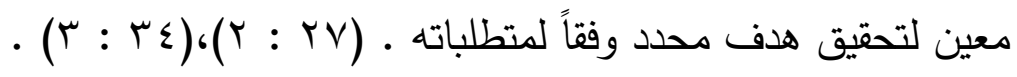

" أخصائى رياضى أول - كلية التربية الرياضية بالعريش - جامعة قناة السويس . 
ومن خلال متابعة للبطولات المحلية والعالمية تبين ارتفاع مستوى الأداء المهارى المندمج الهجومي في

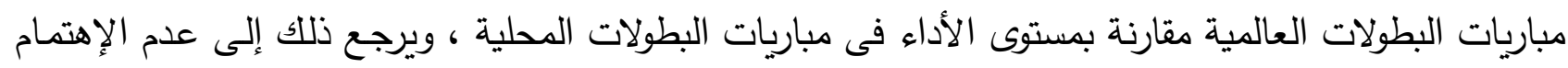

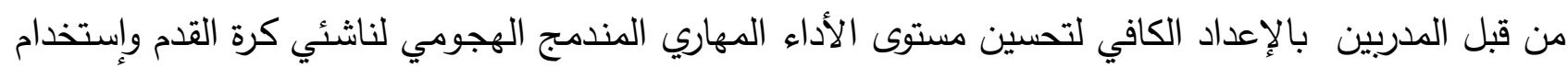

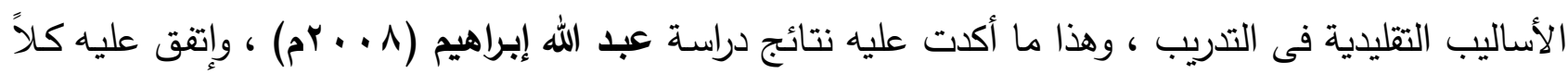

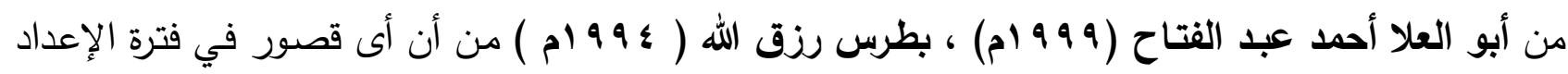

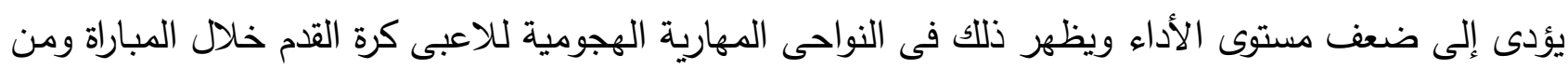

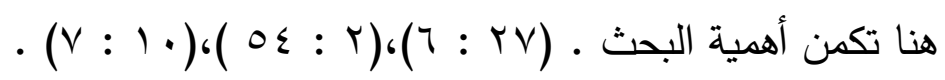
وفى كرة القدم يختلف أسلوب التدريب وطريقته حسب فترة التدريب (فترة الإعداد بمراحلها المختلفة - فترة المنافسات - الفترة الإنتقالية ) لذا كان من الأهمية الوقوف على انسب الطرق والأساليب التى تحقق الهدف من عملية التدريب .

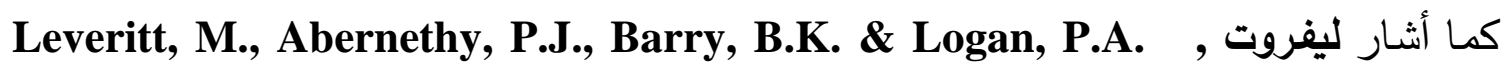

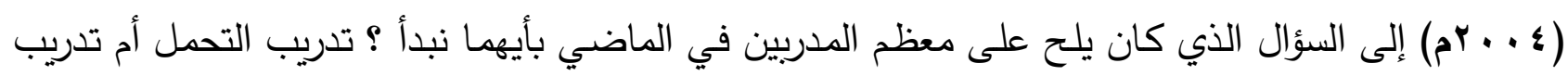

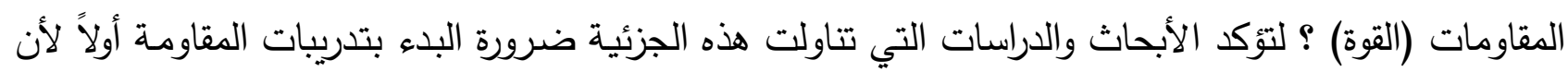

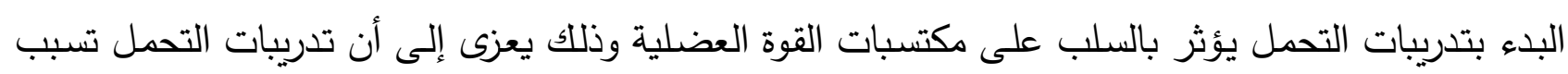

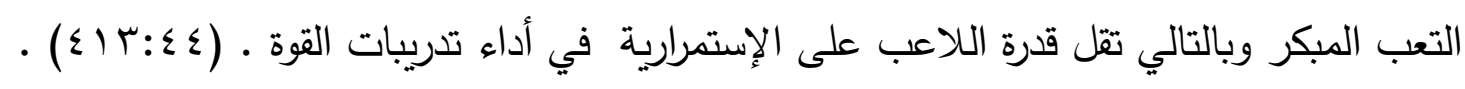

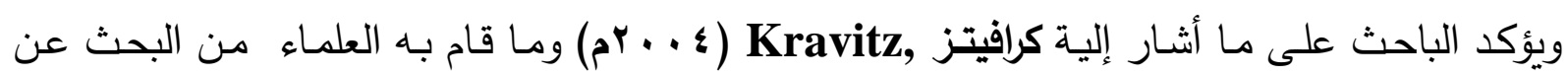

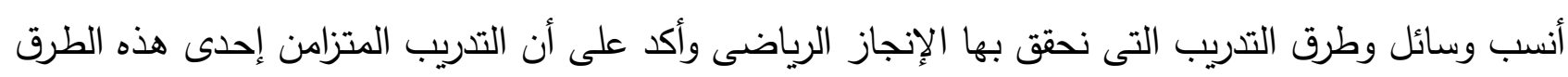

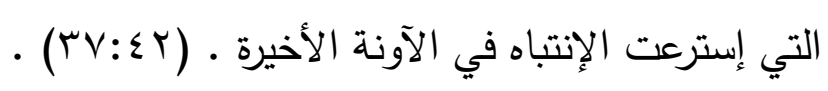

ويتفق كلاً من باتون Patton, C. D., \& Hopkins, W. G. (ه . . . rم) ، عزت إبراهيم السيد

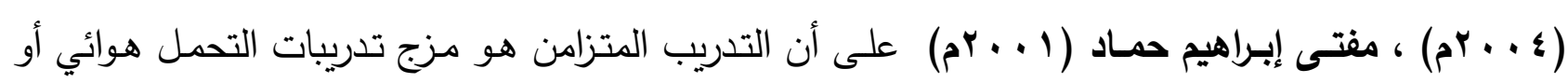

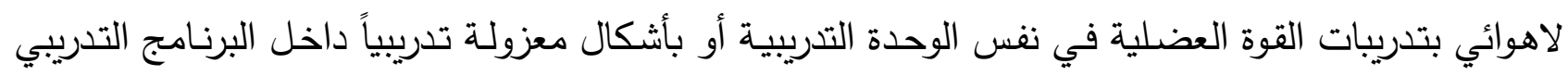

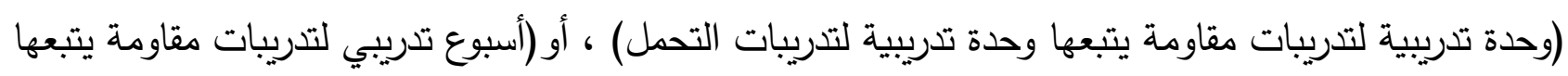

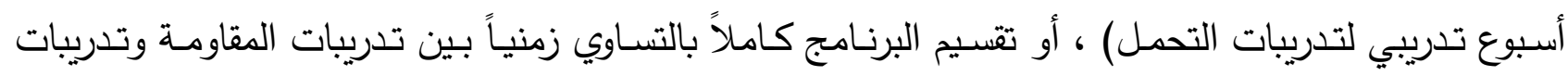

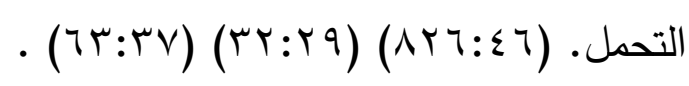

ويعزى الباحث ذلك إلى وجود مشكلة لاى أغلب المدربين فى إختيار الطرق والأساليب المستخدمة فى التى

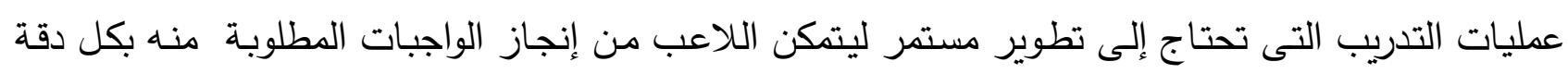
وإتقان.

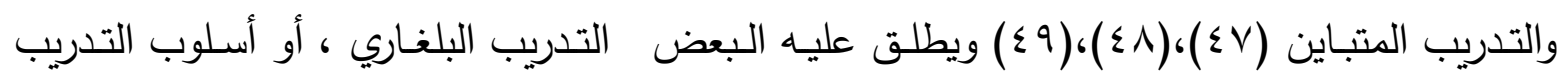

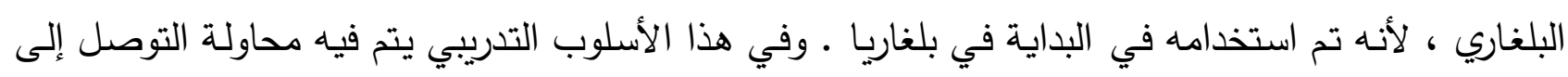


أقصى درجة من الفاعلية عن طريق إستخدام القوة بأساليب متباينة ، أو متضادة ، وذلك داخل الوحدة التدريبية ،

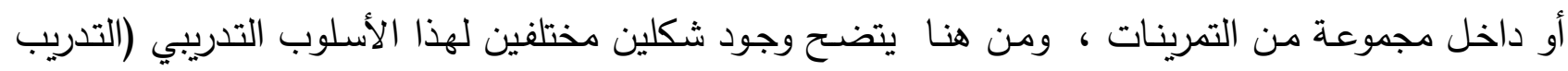

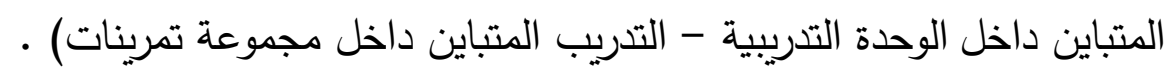

ويهدف أسلوب التدريب المتباين إلى تجنب مسار التدريب على وتيرة واحدة وذلك عن طريق الإقتصار

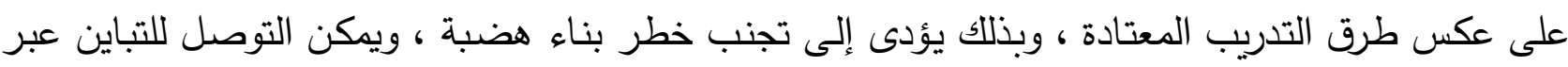

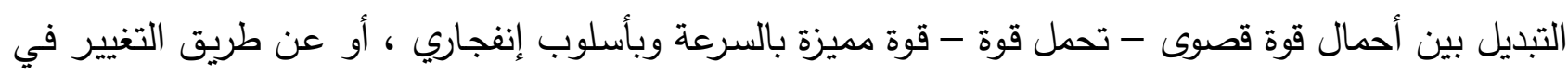

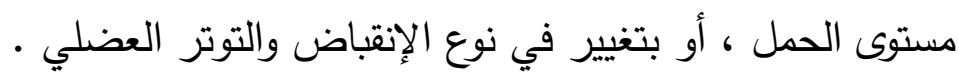
كما أن التدريب المتباين إسلوب يعتمد على مزج تدريبات القوة بوزن الجسم باستخدام تمارين القفز

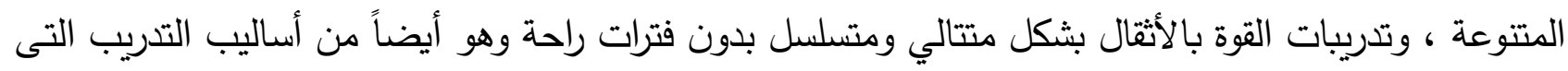
تعطى نتائج كبيرة .

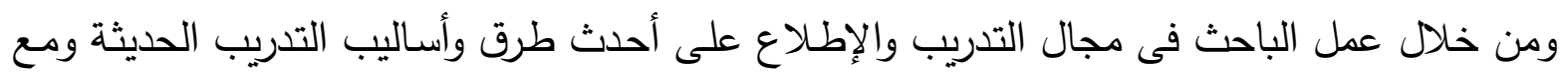
التطور الهائل فى مستوى كرة القدم والتى أصبحت تتميز فى الآونة الأخيرة بالقوة والسرعة فى الأداء كان لأل البد

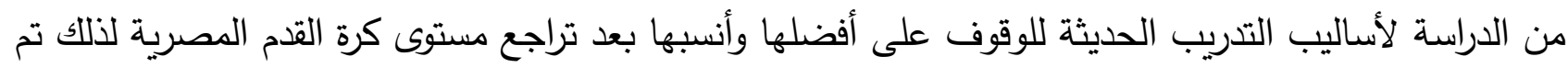

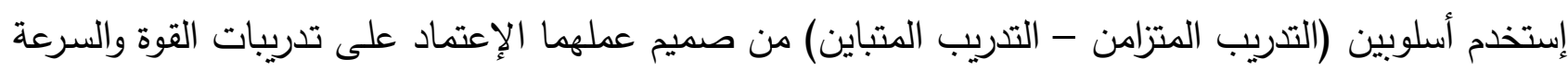

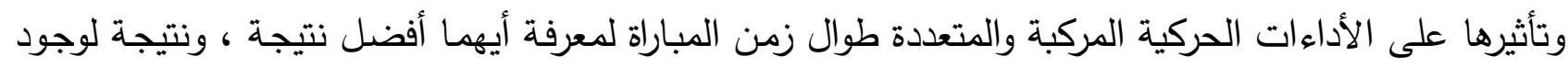

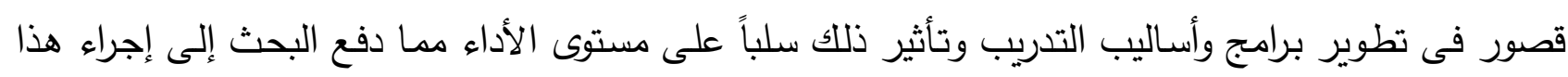
البحث للتعرف على تأثير المتغيرات البدنية الخاصة على مستوى أداء بعض المهارات المندمجة الهجومية وهذا

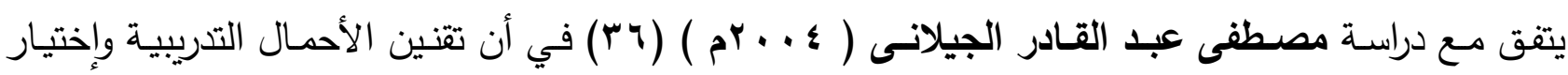

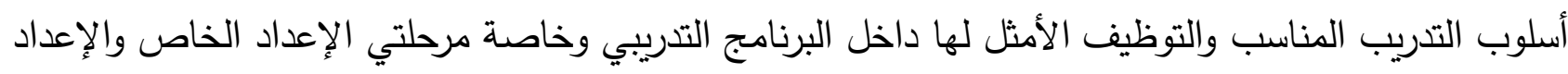

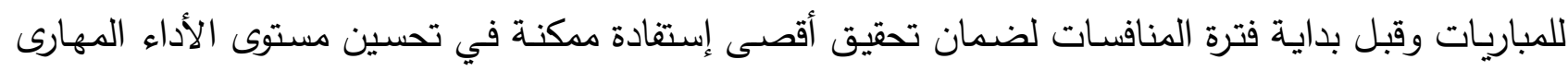

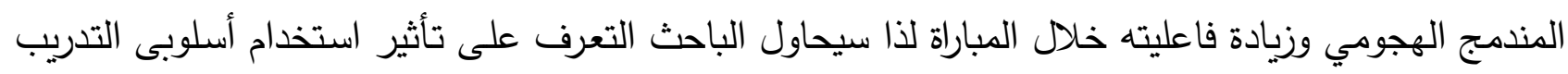

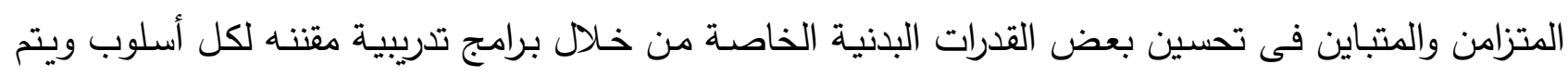

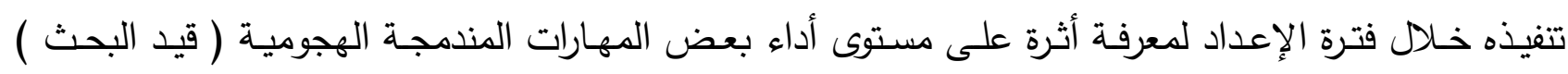
للاعبى كرة القدم .

\section{هدف البحث:}

ويهدف البحث إلى التعرف على تأثير إستخدام أسلوبى التدريب (المتزامن - المتباين ) على تتمية بعض

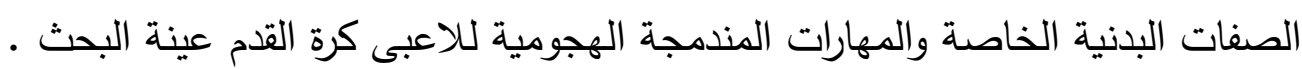


ا ـ توجد فروق دلالة إحصائيأ بين القياس القبلي والبعدي للمجموعة التجربية الأولى فى بعض الصفات البدنية الخاصة والمهارات المندمجة الهجومية لدى للاعبى كرة القدم • r- ت توجد فروق دلالة إحصائيأ بين القياس القبلي والبعدي للمجموعة التجريبية الثانية فى بعض الصفات البدنية الخاصة والمهارات المندمجة الهجومية لدى للاعبى كرة القدم .

r- توجد فروق ذات دلالة إحصائية بين القياسين والبعديين للمجموعة التجريبية الأولى والثانية فى بعض

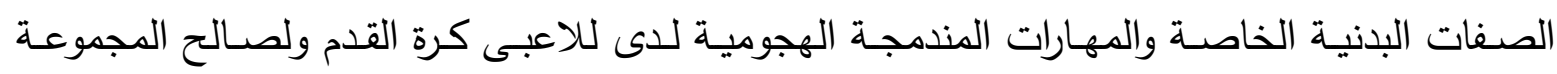
التجريبية الأولى البعاس

بعض الاراسات السابقة :

الدراسـات السـابقة ذات أهمية بالغة وهى نقطة البداية والإنطلاقة الأولى التى يرتكز عليها أى باحث لأنه من خلالها يطلع على الخطوات والإجراءات التى سوف يتبعها لمعالجة بحثه والمضي فيها متبعا خطوات البحث العلمي ، ونعرض بعض الدراسات السابقة العربية والأجنبية وبإجمالى (r I ( دراسة عربية وأجنبية وبواقع

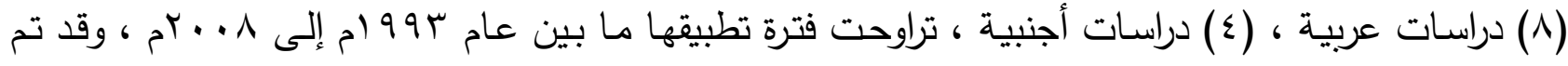
عرض هذه الدراسات طبقاً للترتيب الزمني من الأحداث إلى الأقدام على النحو التالي : أولاًً : الاراسات العربية

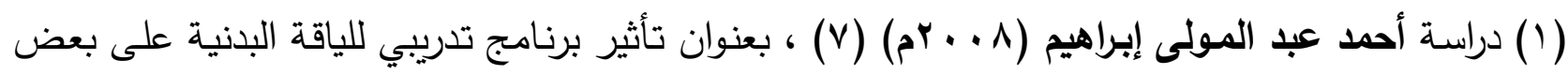
الاستجابات الوظيفية وفعالية الأداء المهارى المركب لناشئى كرة القدم ، وتهدف إلى التعرف على تأثير برنامج

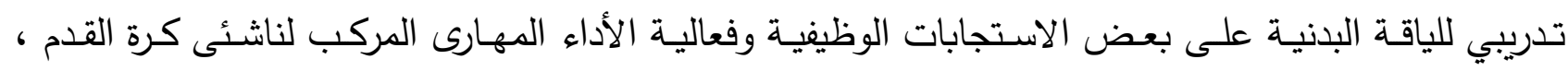
واستخدم الباحث المنهج التجريبى على عينة قوامها (0) ناشئ تحت ؛ ا سنة ، وكانت أهم النتائج أن البرنامج التدريبي المقترح يؤدى إلى الإرتقاء بكل من المستوى المهارى والبدنى والمتغيرات الوظيفية للمجموعة التجريبية قيد البحث .

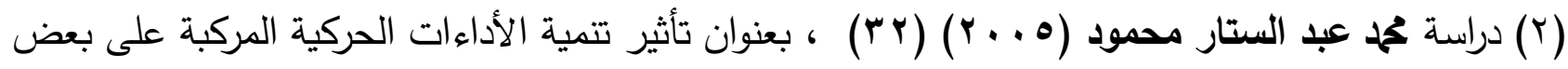
مكونات اللياقة البدنية الخاصة للناشئين في كرة القدم ، وتهدف إلى تأثير تتمية الأداءات الحركية المركبة على بعض مكونـات اللياقة البدنيـة الخاصـة للناشئين في كرة القدم ، واستخدم الباحث المنهج التجريبى على عينة قوامها (צ Y) ناشئ ، وكانت أهم النتائج تنمية الأداء المهارى من خلال تدريبات الأداءات الحركية المركبة يؤدى إلى الارتقاء بكل من المستوى المهارى والبدنى ومن ثم اختصار الزمن الكلى لأحجام التدريب المؤثر واستغلاله

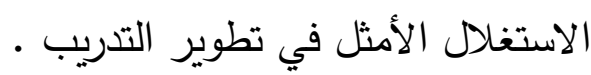

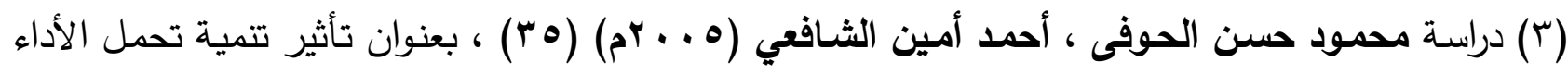
على معدل إنتاجية بعض المهارات المندمجة الهجومية لناشئ كرة القدم ، وتهدف إلى التعرف على تأثير 
برنامج تدريبي لتتمية تحمل الأداء على(مستوى أداء ، معدل إنتاجية) بعض المهارات المندمجة الهجومية ،

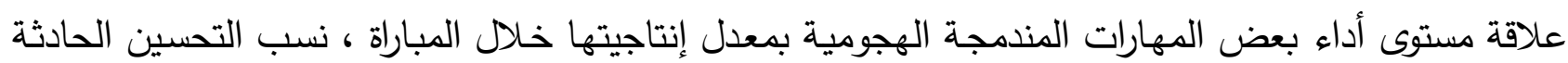

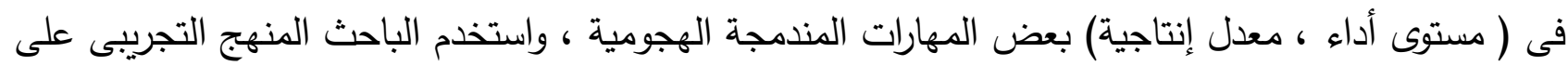

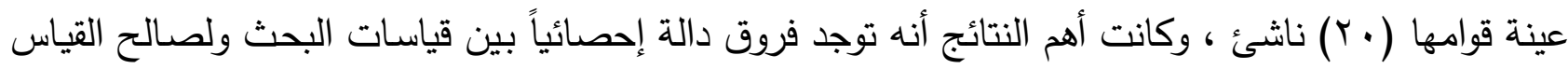

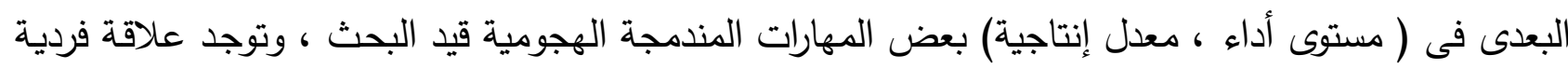

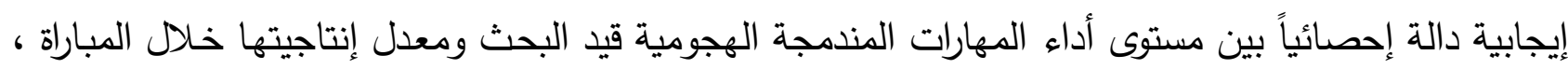

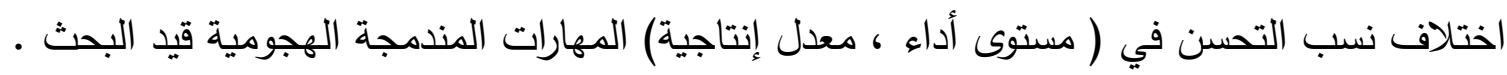

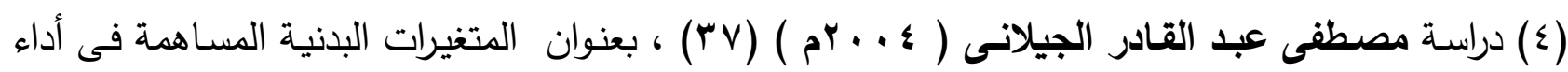

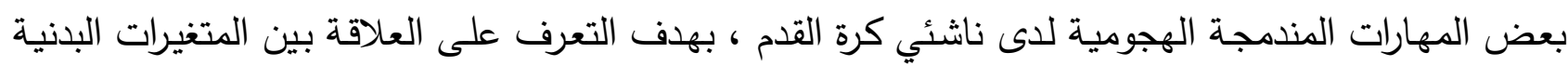

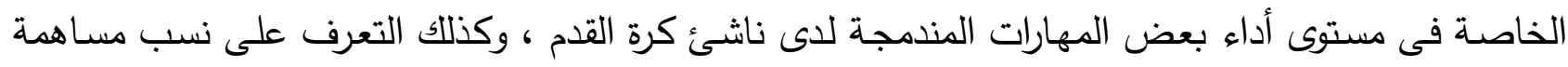
المتغيرات البدنية الخاصة فى مستوى أداء بعض المهارات المندمجة الهجومية لاى ناشئ كرة القدم ، واستخدم

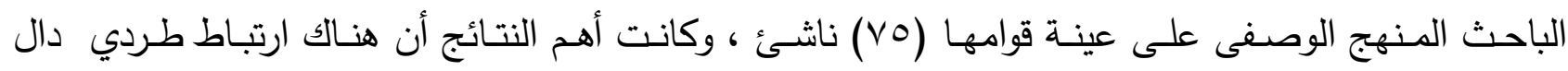

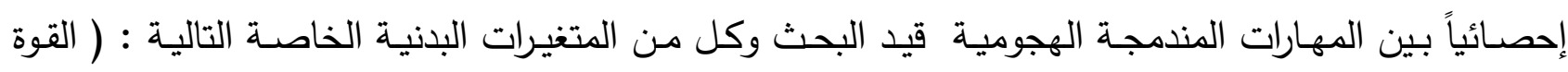

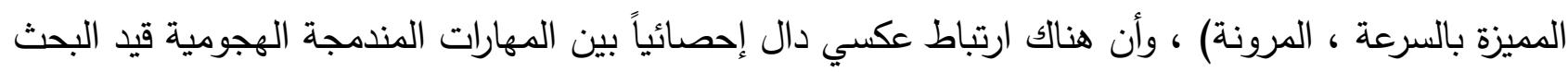

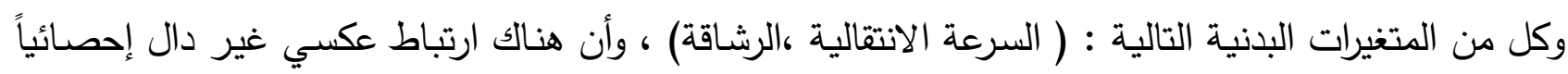

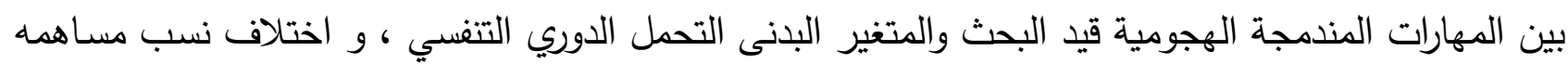

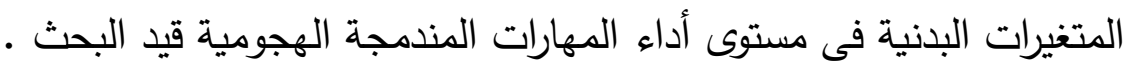

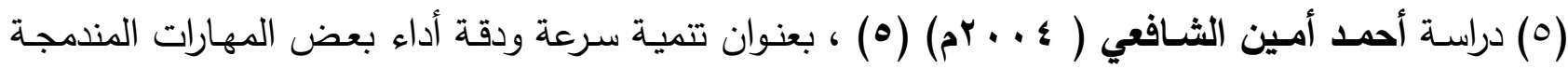

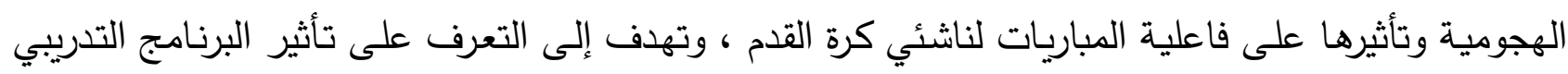

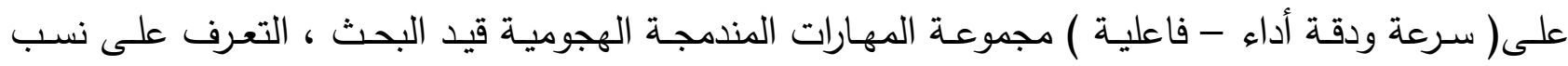

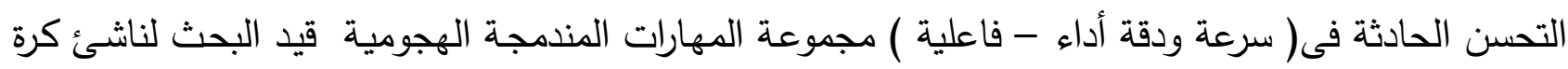

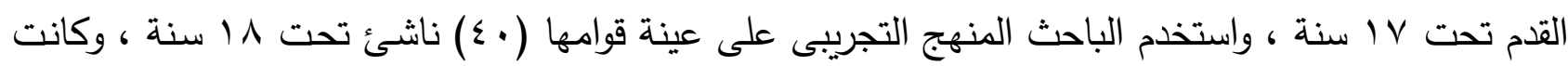

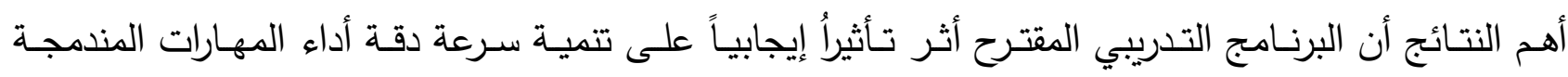

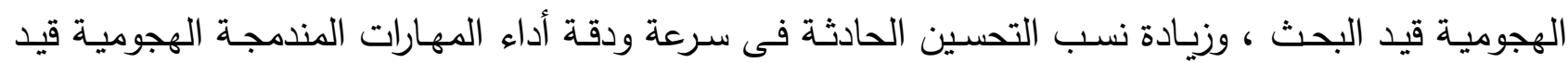

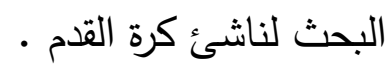

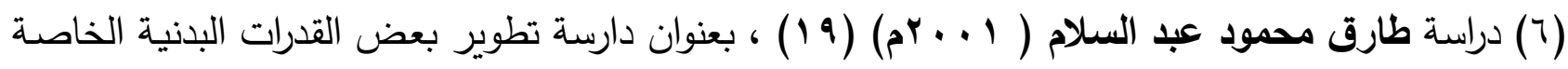

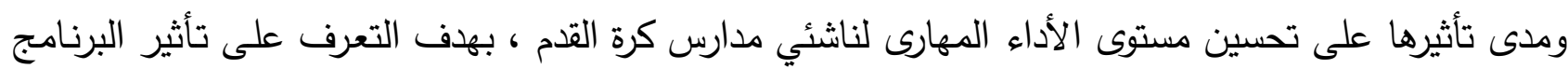

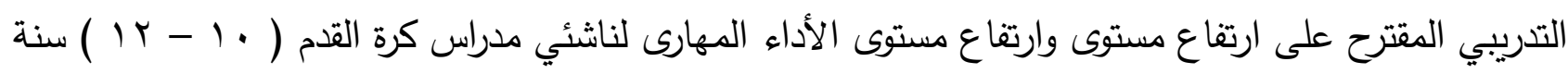

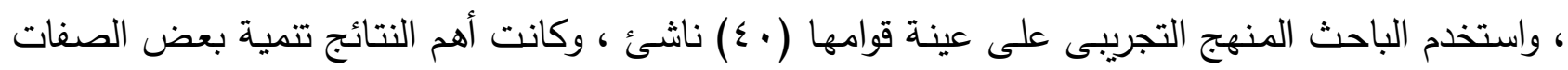

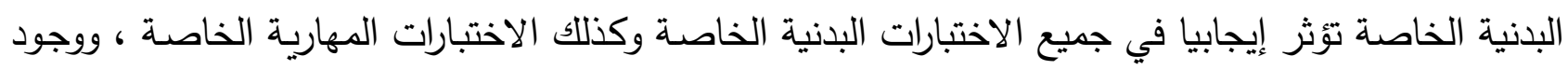


علاقة ارتباطيه دالة إحصائياً بين بعض الاختبارات البدنية المستخدمة وبعض الاختبارات المهارية التى تقيس

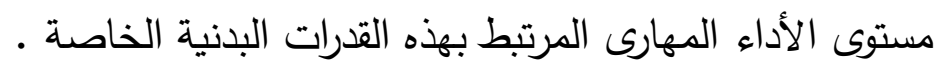

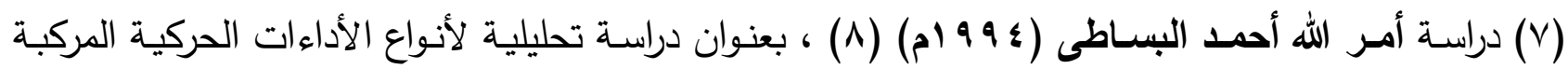

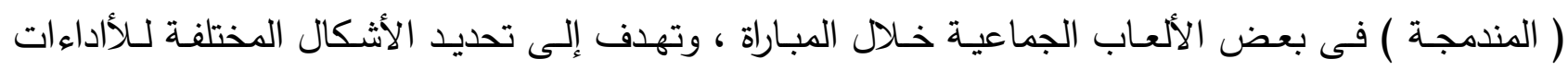

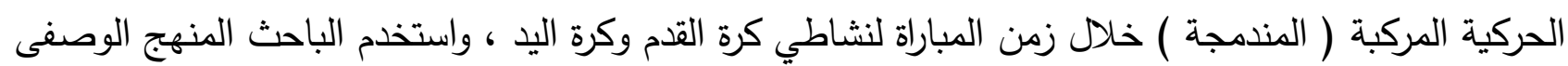

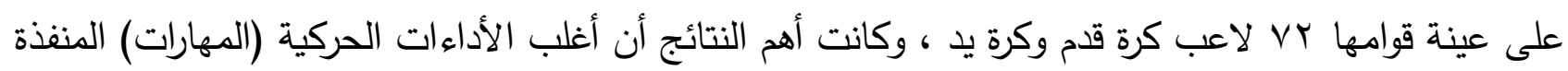

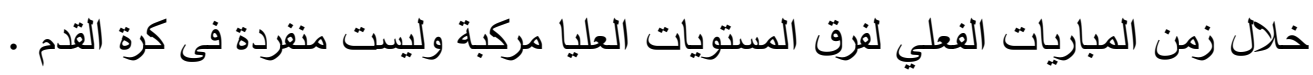

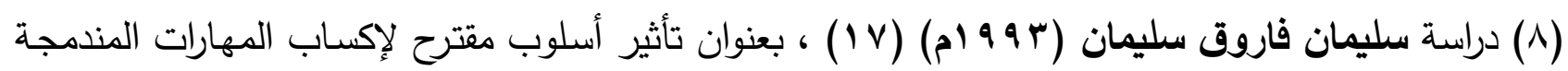

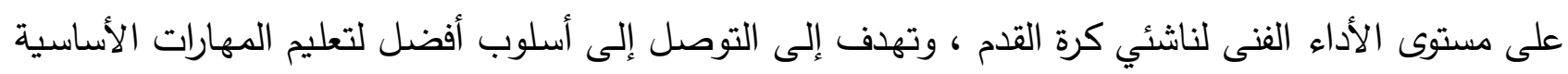

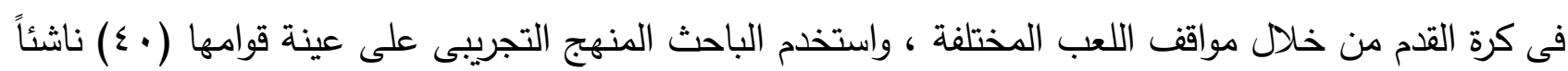

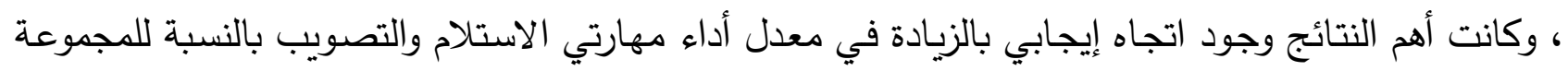

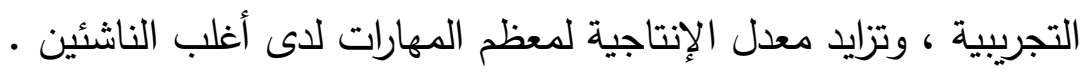
ثانياً : الاراسات الأجنبية : الإندان

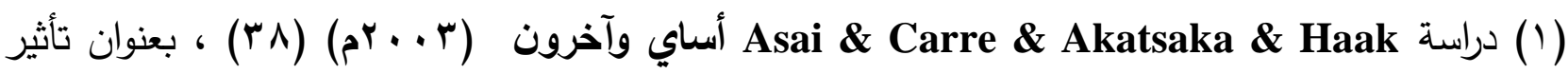
تخطيط مرحلة الإعداد الخاص على مستوى الأداء المهارى لاى ناشئي كرة القدم وتهدف إلى التعرف على تأثير

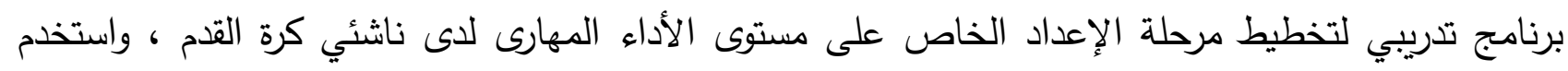

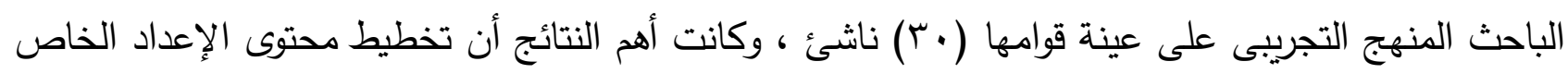

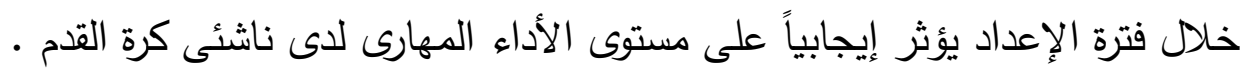

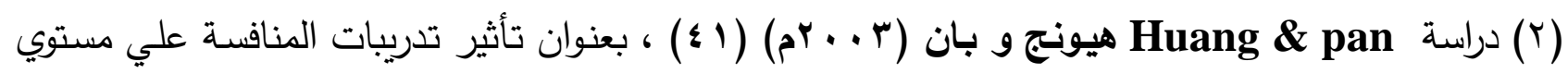

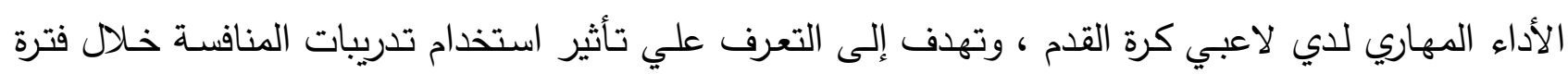

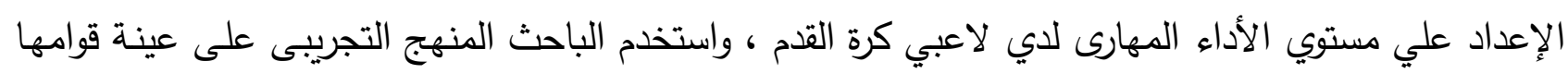

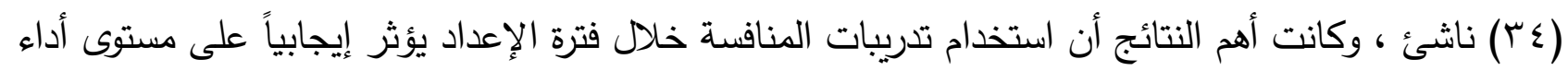
المهارات قيد البحث .

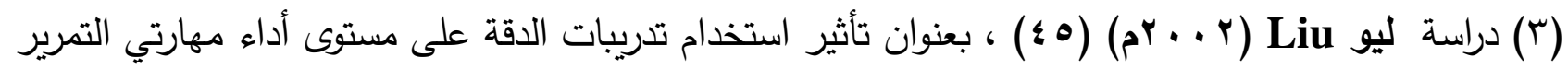

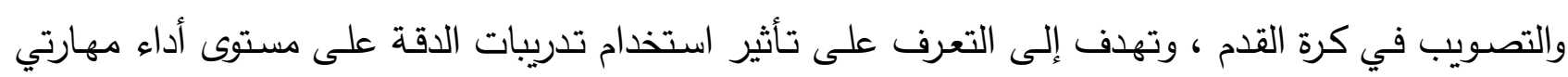

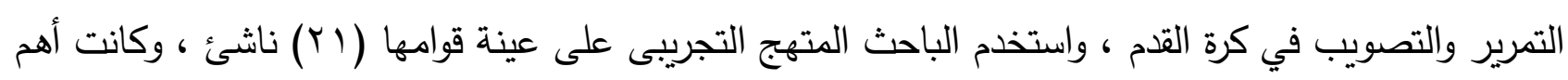

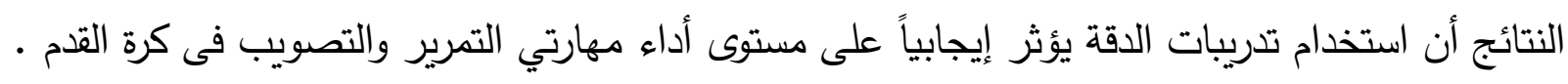

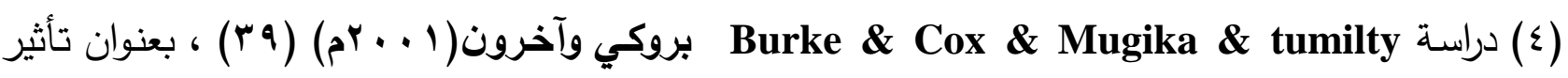
تتمية المتغيرات البدنية الخاصة على مستوى الأداء المهارى لدى ناشئي كرة القدم ، بهدف التعرف على تأثير

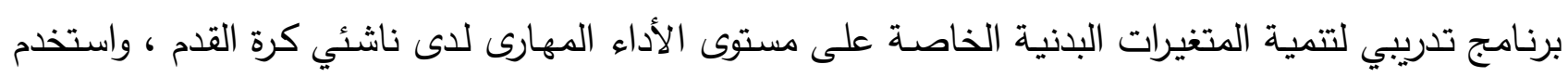

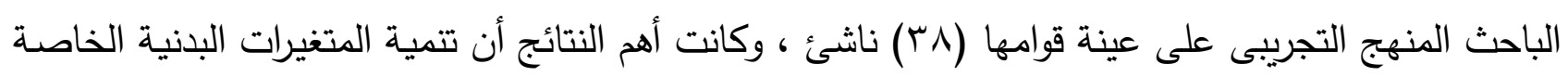


يؤثر إيجابياً على مستوى الأداء المهارى لدى ناشئى كرة القدم ، ووجود علاقة ارتباطيه دالـة إحصـائيا بين

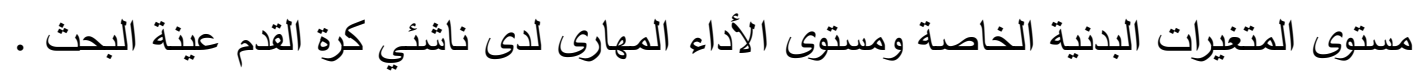

\section{خطة وإجراءات البحث}

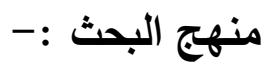

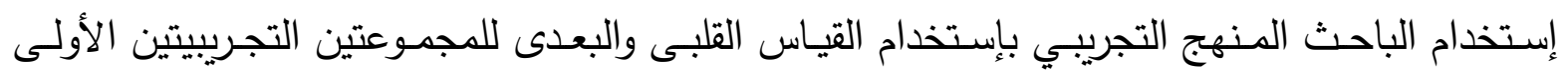

والثانية (عينة البحث الأساسية) وذلك لمناسبته لطبيعة البحث .

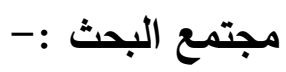

أشتمل مجتمع البحث على لاعبي كرة بنادى نجمة سيناء - بمدينة العريش - محافظة شمال سيناء

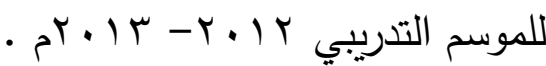

$$
\begin{aligned}
& \text { عينة البحث : }
\end{aligned}
$$

(أ) المجال المكانى : نادى نجمة سيناء - محافظة شمال سيناء - جمهورية مصر العربية .

(ب) المجال البثرى : قام الباحث بإختيار عينـة البحث من لاعبى كرة القدم بنادى نجمة سيناء - بمدينة العريش- محافظة شمال سيناء والمسجلين بالاتحاد المصرى لكرة القدم ، تم إختيارهم بالطريقة العشوائية وتم

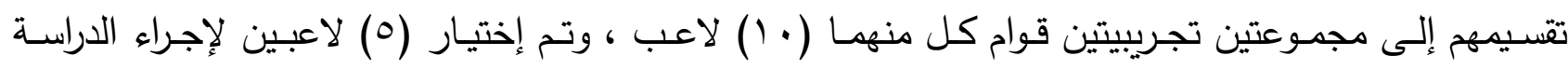

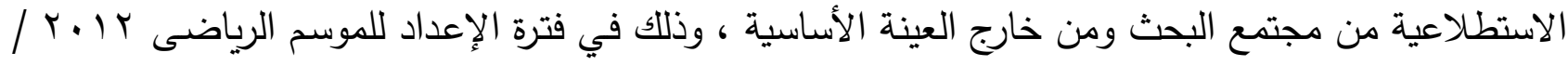

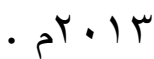

قام الباحث بإجراء التكافؤ بين أفراد عينة البحث الأساسية فى متغيرات (السن ، الطول ، الوزن ، العمر التدريبى) وباقى المتغيرات قيد البحث والجدولين (l، ؟) يوضح ذلك .

جدول (1)

دلالة الفروق بين متوسطات القياسات القبلية فى متغيرات السن والطول والوزن والعمر التدريبى

\begin{tabular}{|c|c|c|c|c|c|c|c|c|}
\hline \multirow{2}{*}{ الدلالة } & \multirow{2}{*}{ قلمة } & \multirow{2}{*}{ الفترق بين } & \multicolumn{2}{|c|}{ التجريبية الثانية } & \multicolumn{2}{|c|}{ التجريبية الأولى المجوعة } & \multirow[t]{2}{*}{ وحدة } & \multirow{2}{*}{ الاختبار الإحصائي } \\
\hline & & & $\varepsilon \pm$ & س & $\varepsilon \pm$ & س & & \\
\hline
\end{tabular}
بين أفراد المجموعتين التجريبيتين الأولى والثانية .

$1 \cdot=r \dot{0}=10$ 


\begin{tabular}{|c|c|c|c|c|c|c|c|c|c|}
\hline غير دال & .911 &.$r r$ & $\cdot .9 \leq$ & $r . .17$ &.$v 1$ & $19.1 \mathrm{r}$ & سنة & السن & \\
\hline غير دال &.$r q$ & $\cdots \leqslant Y$ & r.rr & 179.17 & Y.AV & 179.01 & سم & الطول & i] \\
\hline غير دال & .or &. .01 & 1.99 & $v \cdot .0$. & T.Y. & 79.91 & كجم & الوزن & \\
\hline غير دال & I.rr &.$r r$ &.$r q$ & V.r $\varepsilon$ & .87 & 7.91 & سنة & العمر التدربيى & \\
\hline
\end{tabular}

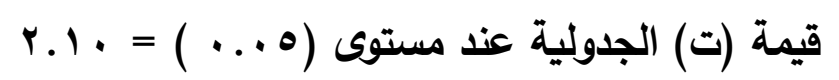

يتضـح مـن الجدول رقم (1) وجـود فروق دالـة إحصـائياً بين متوسطات القياسـات القبليـة للمجموعـة

التجريبية الأولى والمجموعة التجريبية الثانية فى متغيرات السن والطول والوزن والعمر التدريبى وأن قيمة (ت) المحسوبة لتلك المتغيرات أقل من قيمتها الجدولية مما يدل على تكافؤ تلك المتغيرات .

\section{جدول (r)}

دلالة الفروق الإحصائية بين متوسطات القياسات القبلية فى متغيرات الصفات البدنية الخاصة والمهارات الهجومية المندمجة قيد البحث بين أفراد المجموعتين التجريبيتين الأولى والثانية .

\begin{tabular}{|c|c|c|c|c|c|c|c|c|c|}
\hline \multirow{3}{*}{ غير دالد } & \multirow{3}{*}{ قالمحسوبة } & \multirow{3}{*}{ الفتوسطين بين } & \multicolumn{2}{|c|}{ المجموعة التجربيبة } & \multicolumn{2}{|c|}{ المجموعة التجربية } & \multirow{3}{*}{ وحدة } & \multirow{2}{*}{ الإحصاء } & \multirow{6}{*}{ 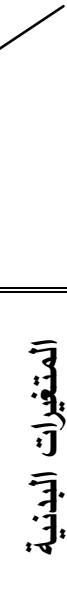 } \\
\hline & & & \multirow{2}{*}{$\frac{\varepsilon \pm}{.17}$} & \multirow{2}{*}{$\frac{\omega}{0.19}$} & \multirow{2}{*}{$\frac{\varepsilon \pm}{.11}$} & \multirow{2}{*}{ س } & & & \\
\hline & & & & & & & & السرعة الانتقالية & \\
\hline غير دال & .07 & $\ldots r$ & $\ldots v$ & $r . r r$ & $.1 r$ & r.rq & متر & القوة المميزة بالسرعة & \\
\hline غير دال &.$r q q$ & $\ldots r$ & $\ldots 0$ & $V .\{1$ & .ro & $V . \varepsilon \varepsilon$ & ثانية & الرشاقة & \\
\hline غير دال & $\cdot . \leq \varepsilon$ & .7 & $.7 \mathrm{~V}$ & or. 9 . & .rr & or.o. & سم & المرونة & \\
\hline غير دال &. .17 &..$r$ &.$r q$ & \&.VY &.$r v$ & \&.V० & ثانية & & $\overline{3}$ \\
\hline غير دال &. .09 &. $.1 \mathrm{~V}$ & $.7 \mathrm{~V}$ & $1 . \varepsilon r$ &.$v r$ & 1.50 & درجة & & $\overline{5}$ \\
\hline غير دال & .99 &. .17 & $\ldots \leqslant 1$ & $\varepsilon \ldots 7$ & $\cdots \leqslant 1$ & $r .91$ & ثانية & السيطرة ثم الجرى & ; \\
\hline غير دال & $1.7 \mathrm{~V}$ & $\therefore 0$ & .01 & 1.01 & .9 & 1.11 & درجة & بالكرة ثم التمرير & $8:$ \\
\hline غير دال & $1 . .0$ & $\cdots 1$ & .47 & $r .\{\Lambda$ & .1 & r.s. & ثانية & السيطرة ثم الجرى & .3 \\
\hline غير دال & $. v \leq$ & .ro & $\therefore 9$ & 1.0. & $\because v_{0}$ & $1 . r 0$ & درجة & بالكرة ثم التصويب & : \\
\hline غير دال &..$\wedge \varepsilon$ &. .14 &.$Y r$ & \&.rq &. Yo & $\leq . \leq \wedge$ & ثانية & السيطرة ثم المراوغة ثم & $\overline{7}$. \\
\hline غير دال &.$r \varepsilon$ &.$\Delta r$ & $\ldots v q$ & $1 . \varepsilon r$ &. .19 & 1.rr & درجة & & .9. \\
\hline
\end{tabular}


يتضح من جدول (Y) وجود فروق دالة إحصائياً بين متوسطات القياسات القبلية للمجموعة التجريبية

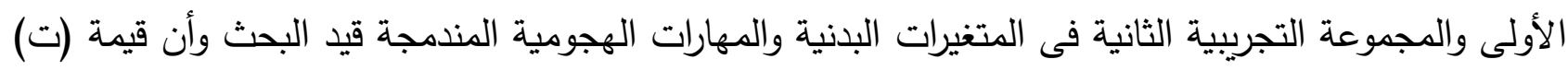
المحسوبة لتلك المتغيرات أقل من قيمتها الجدولية مما يدل على تكافؤ تلك المتغيرات . : أدوات ووسائل جمع البيانات : (1) الأجهزة والأدوات المستخدمة في البحث : • • • • ميزان طبي معاير لقياس الوزن قراس طبية مقاعد سويدية وصناديق بإرتفاعات مختلفة. أثقال بأوزان مختلفة .

(r) الاختبارات البذنية الخاصة والمهارات المندمجة الهجومية المستخدمة في البحث : أولاً : الإختبارات البدنية الخاصة قيد البحث مرفق (1) . حدد الباحث المتغيرات والاختبارات البدنية والتى يمكن من خلالها إجراء تجانس افراد عينة البحث وكذلك تطبيق

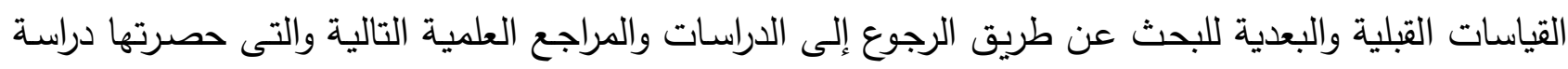

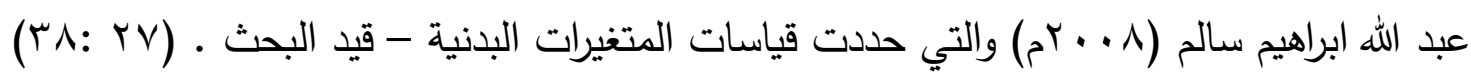

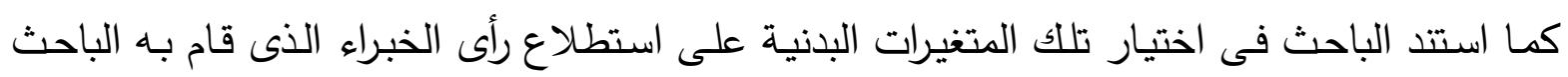

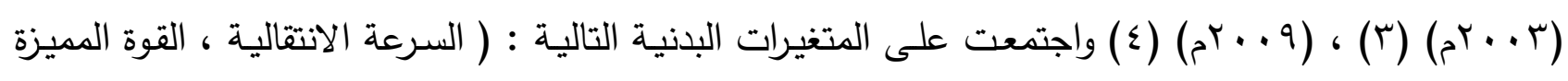

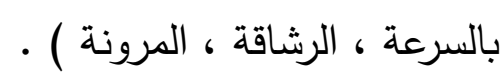

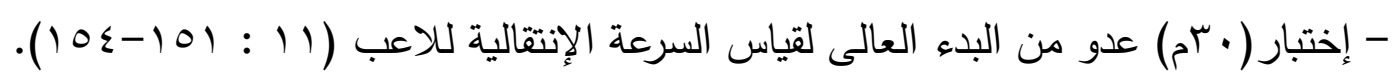

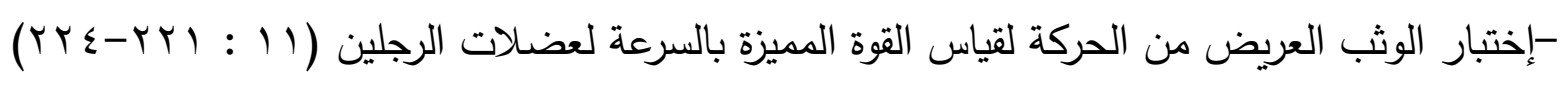

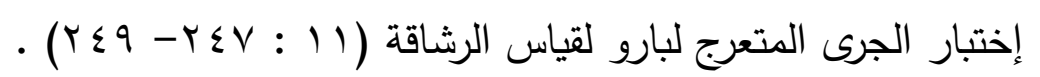

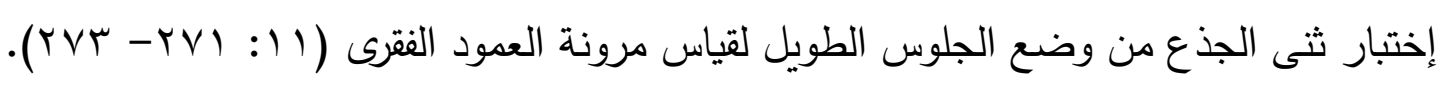

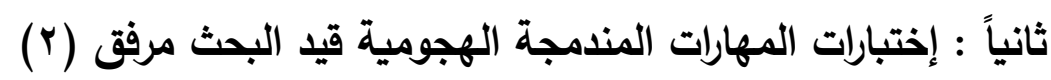

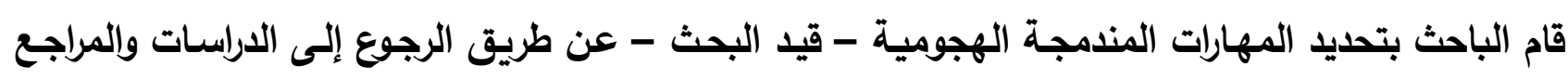

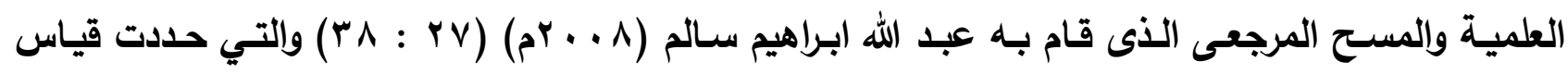

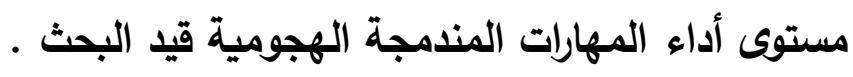

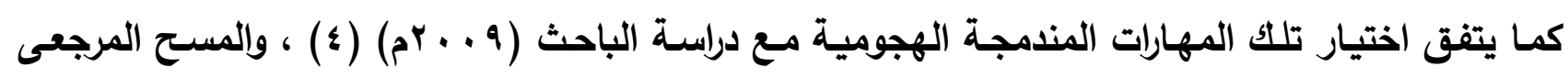

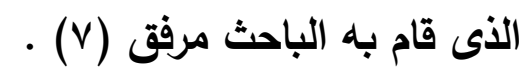
- إختبار السيطرة ثم التمرير لقياس السيطرة على الكرة ثم التمرير - 
- إختبار السيطرة ثم الجرى بالكرة ثم التمرير لقياس السيطرة على الكرة ثم الجرى بالكرة ثم التمرير -

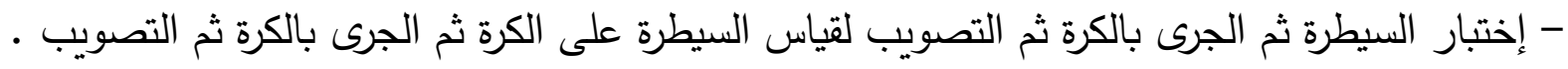

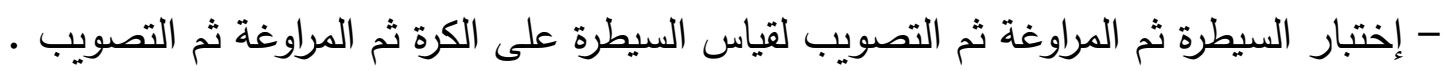

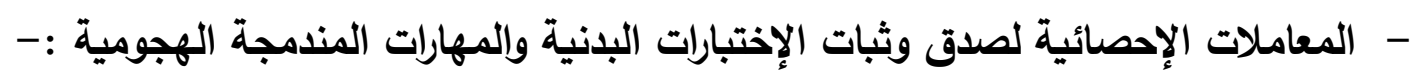

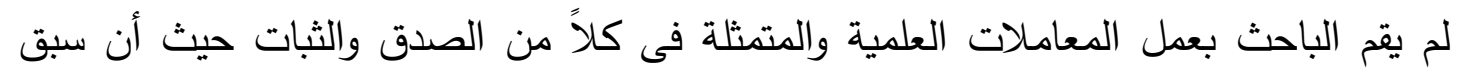
إستخدام تلك الاختبارات البدنية والمهارات المندمجة الهجومية على لاعبى كرة القدم فى دراسات عبد الله

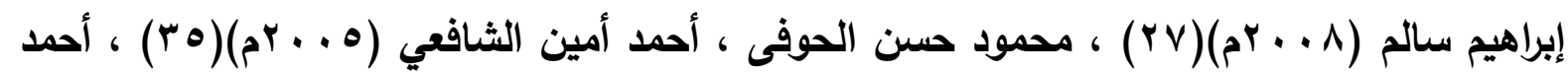

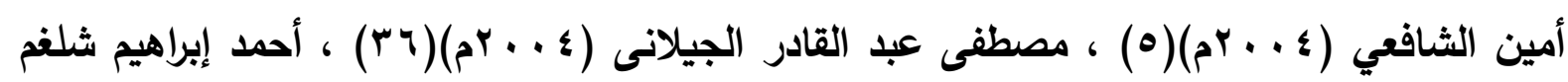

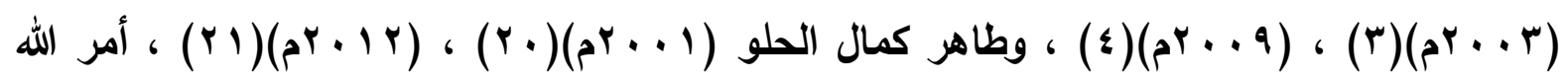

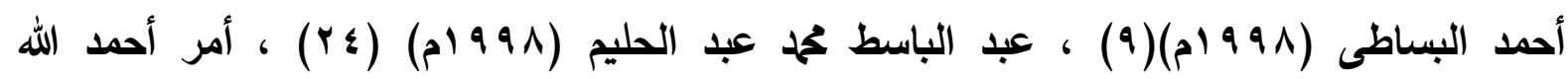

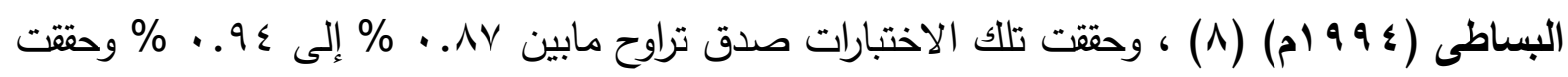

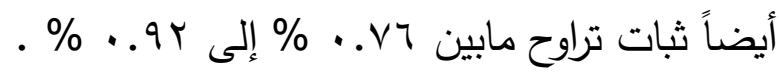

$$
\text { (r) ( أسلوب المسح المرجعي }
$$

1- المسح المرجعي حول المتغيرات البلنية الخاصة والمهارات المندمجة :-

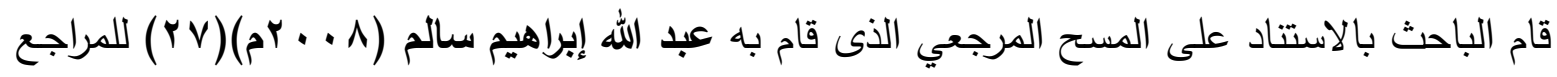

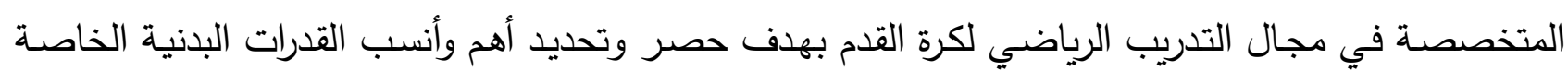

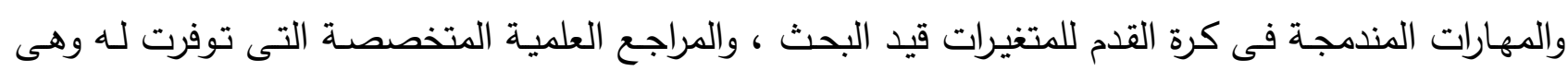

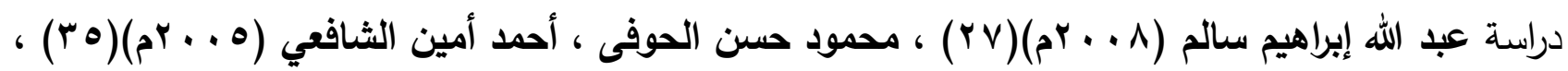

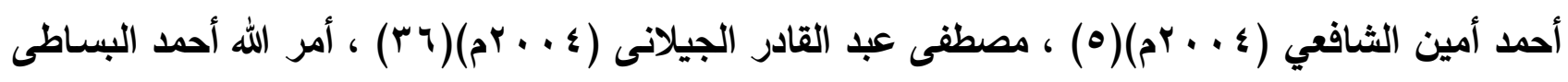

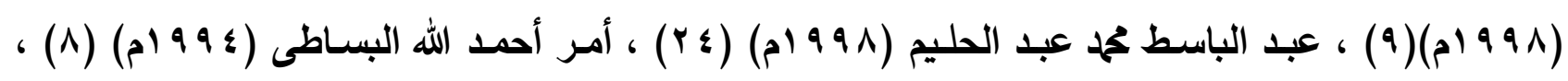
والتى تتاولت تحليل وتحديد المتغيرات البدنية الخاصة ، المهارات المندمجة الهجومية المؤثرة فى نتائج المباريات

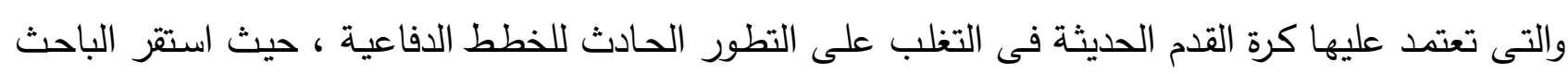

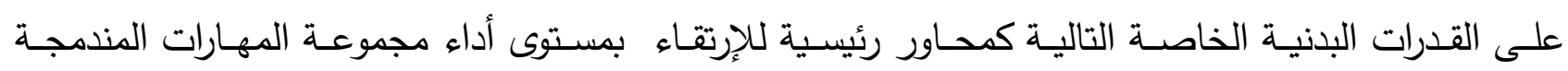

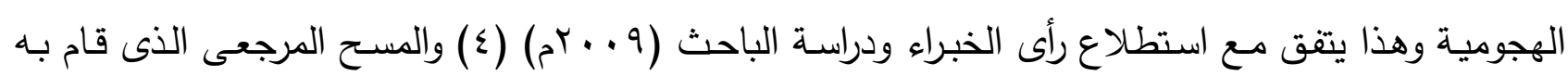

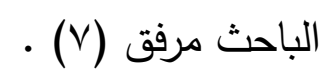

- المتغيرات البذنية الخاصة : (السرعة الإنتقالية - القوة المميزة بالسرعة - الرشاقة - المرونة ) . - المهارات المندمجة الهجومية : (السيطرة ثم التمرير - السيطرة ثم الجري بالكرة ثم التمرير - السيطرة ثم

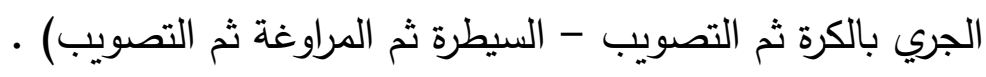
* تخطيط البرنامج التدريبى مرفق (r) . 
* برنامج التدريب المتزامن والمتباين مرفق (؛ ) .

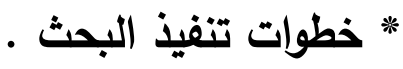

الدراسة الاستطلاعية :

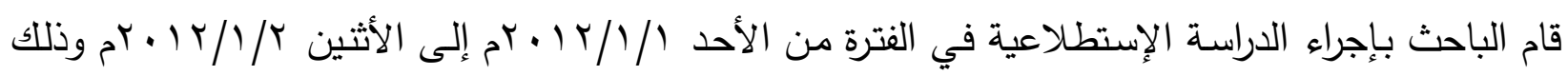

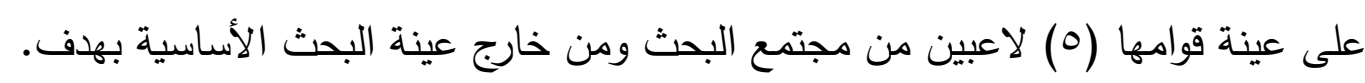

• التحقق من صلاحية الأجهزة المستخدمة في القياس .

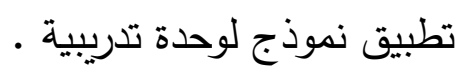

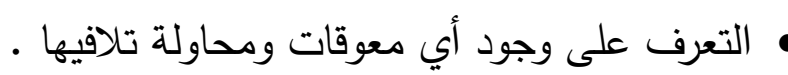

القياسات القبلية :

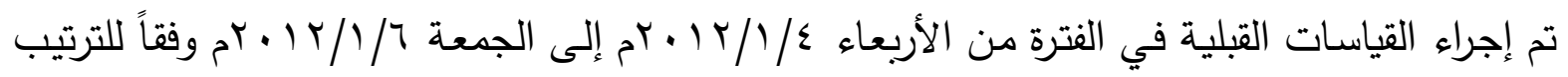
التالي:-

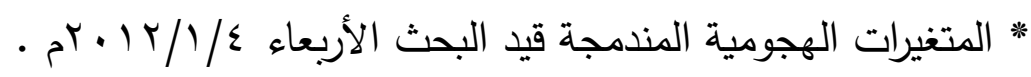

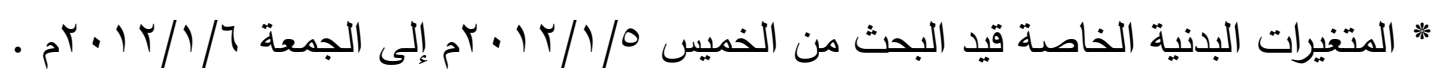
تنفيذ تجربة البحث:

تم تنفيذ تجربة البحث الأساسية على المجموعة التجريبية الأولى والمطبق عليها برنامج التدريب المتزامن

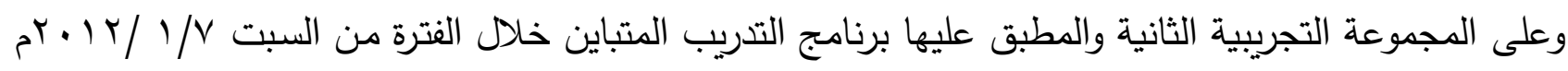

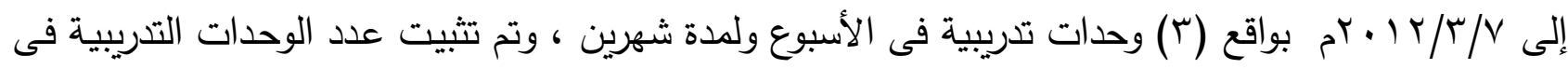

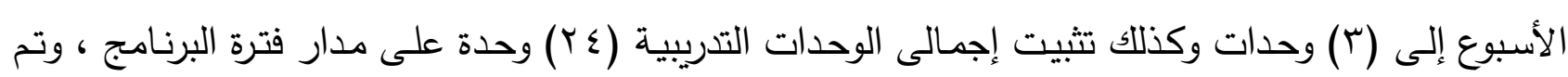
تثبيت زمن الوحدة التدريبية بواقع (•V) دقيقة للوحدة ، وجاء الإختلاف بين البرنامجين فى محتوى البرنامج المتزامن والمتباين .

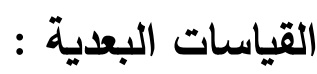

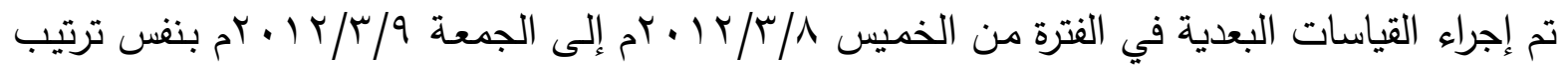
القياسات القبلية.

خطاب تطبيق البحث من نادى نجمة سيناء - بمدينة العريش - محافظة شمال سيناء مرفق (^) . برنامجى التدريب المتزامن والمتباين مرفق (؛ ) ويهدفا البرنامجين المقترحين بإستخدام تدريبات الأسلوب المتزامن والمتباين إلى تتمية وتطوير مستوى

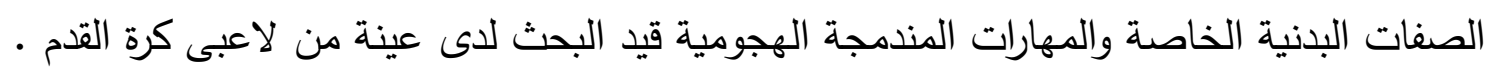


التوزيع الزمني للبرنامج التدريبي المقترح :

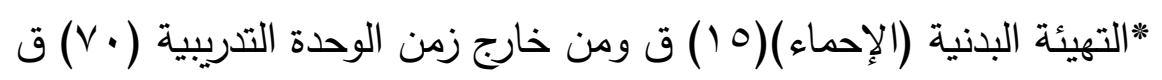

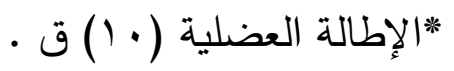

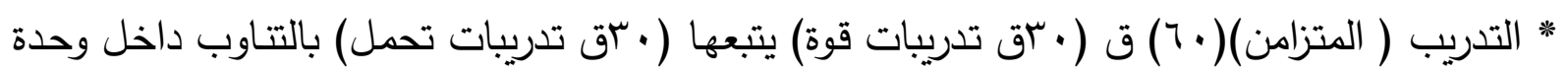

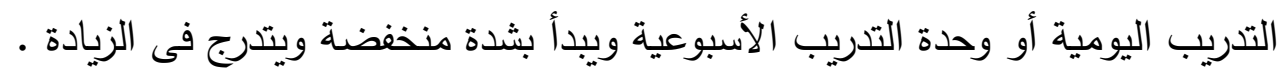

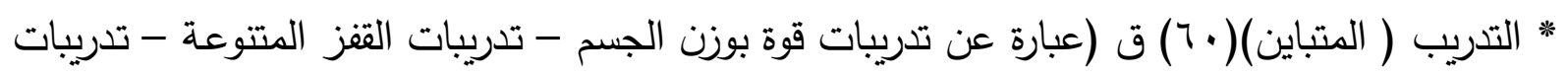

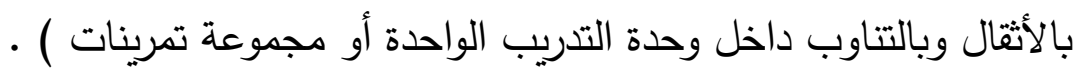

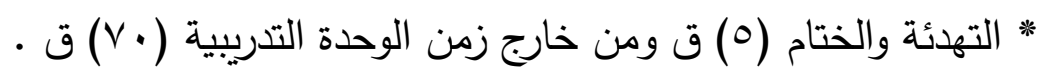

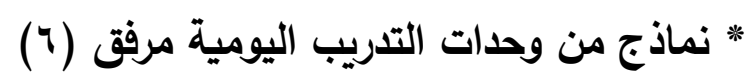

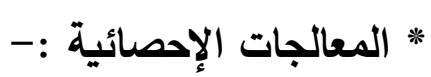

إستخدم الباحث حزمة البرنامج الإحصائى للعلوم الإجتماعية (spss) فى إيجاد التكافؤ وحساب دلالة الفروق

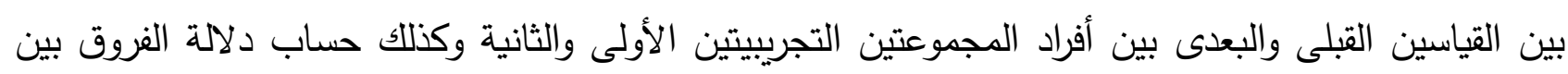

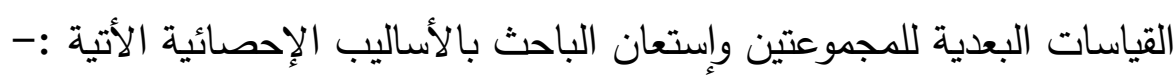

* معادلة إختبار (ت)

للطرفين

$$
\begin{aligned}
& \frac{r^{r}-1 \omega}{\frac{1}{r+{ }^{r}{ }^{r} \varepsilon}}=ت
\end{aligned}
$$

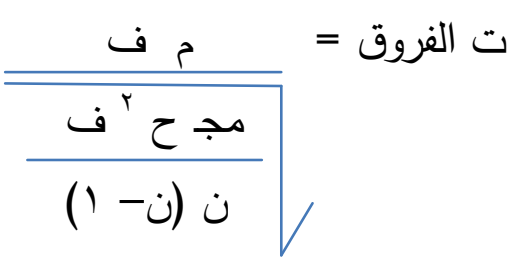

وقد ارتضى "الباحث" مستوى اللالالة الإحصائية عند ( ه . . ) . 
عرض ومناقشة النتائج

فى ضوء الأسلوب الإحصائي المستخدم والنتائج التى توصل إليها يقوم الباحث بعرض النتائج التى تم

أولاً : عرض التوصل إليها كالآتي :-

جدول (r)

دلالة الفروق بين متوسطات القياسات القبلية والبعديه فى كلاً من متفيرات الصفات البلنية الخاصة

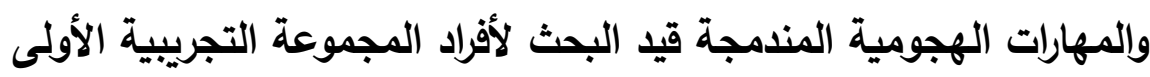

والتى استخدمت التريب المتزامن

1.

\begin{tabular}{|c|c|c|c|c|c|c|c|c|}
\hline \multirow{3}{*}{ مستوى } & \multirow{3}{*}{ قالمحسوتة } & \multirow{3}{*}{ المتوسطين } & \multicolumn{4}{|c|}{ المجموعة التجربيبة الأولى (تدريب متزامن) } & \multirow{3}{*}{ القياس } & \multirow[t]{3}{*}{ الإحصاء } \\
\hline & & & \multicolumn{2}{|c|}{ القياس البعدى } & \multicolumn{2}{|c|}{ القياس القبلى } & & \\
\hline & & & $\varepsilon \pm$ & س & $\varepsilon \pm$ & س & & \\
\hline 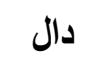 & r.9r & .10 & $\cdots \wedge$ & $\varepsilon .9 V$ &. .11 & 0.17 & ثانية & السرعة الانتقالية \\
\hline 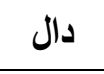 & $\{.79$ &.$r_{0}$ & .19 & r.Tr &. $.1 r$ & r.rY & 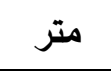 & القوة المميزة بالسرعة \\
\hline 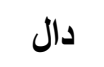 & $r .91$ &.$r q$ &. rr & $v . \wedge \wedge$ &.$r_{0}$ & $V . \varepsilon \varepsilon$ & ثانية & الرشاقة \\
\hline 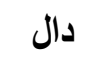 & $9 .$. & T.r. & r.Ao & Mr.A. & r.rY & or.o. & سم & المرونة \\
\hline 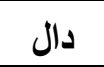 & r.VV &.$r T$ &.$r \wedge$ & «. &.$r v$ & s.vo & ثانية & \\
\hline 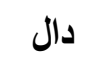 & r... &. $.7 \mathrm{~V}$ &.$\vee V 7$ & $1.9 r$ &.$V r$ & 1.ro & درجة & \\
\hline 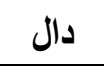 & $\varepsilon .11$ &. .01 & .rr & $\varepsilon . \varepsilon 1$ & 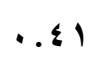 & r.91 & ثانية & السيطرة ثم الجرى بالكرة \\
\hline دال & r.Y &.$v 1$ &. .01 & 1.19 & .9 . & $1 . .1$ & درجة & ثم التمرير \\
\hline دال & E.YV & $. .1 \leqslant$ & .90 & r.Y & .1 & r.s. & ثانية & السيطرة ثم الجرى بالكرة \\
\hline دال & $\varepsilon .79$ & $1 \ldots$ & $\rightarrow \leqslant 0$ & Y.ro & $\because v_{0}$ & 1.Yo & درجة & ثم التصويب \\
\hline دال & $\{.11$ &. .19 & $. .1 \leq$ & $\varepsilon . q^{\prime}$ &. ro & $\{. \leqslant \wedge$ & ثانية & السيطرة ثم المراوغة ثم \\
\hline دال & $r . \cdot V$ & $1 \ldots$ &. .70 & T.MT &. .19 & I.rr & درجة & التصويب \\
\hline
\end{tabular}

$$
\text { قيمة (ت) الجدولية عند مستوى (0. . ) = }
$$

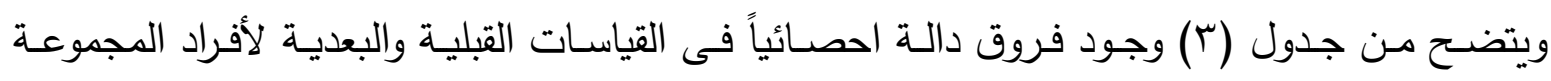

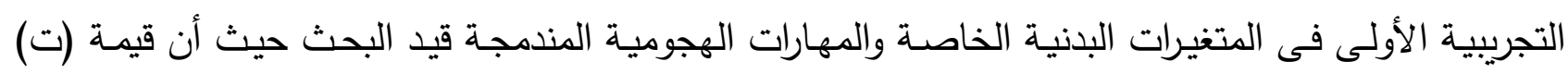

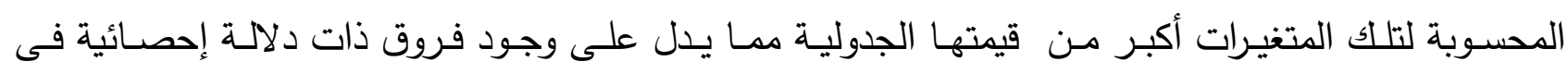
المتغيرات البدنية الخاصة والمهارات الهجومية المندمجة لصالح القياس البعدى للمجموعة التجريبية الأولى والتى

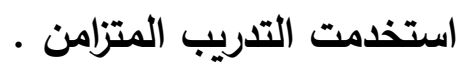


جدول (๕)

دلالة الفروق الإحصائية بين متوسطات القياسات القبلية والبعدية فى كلاً من متغيرات الصفات البدنية

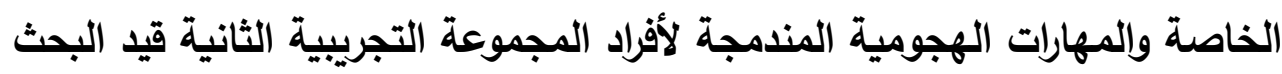

والتى استخدمت التدريب المتباين .

\begin{tabular}{|c|c|c|c|c|c|c|c|c|c|}
\hline \multirow{3}{*}{ مستوى } & \multirow{3}{*}{ قالمحسوبة } & \multirow{3}{*}{ الفرق بين } & \multicolumn{4}{|c|}{ المجموعة التجربيية الثانية (تدريب متباين) } & \multirow{3}{*}{ وحدة القياس } & \multirow{3}{*}{ الإحصاء } & \\
\hline & & & \multicolumn{2}{|c|}{ 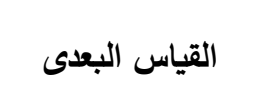 } & \multicolumn{2}{|c|}{ القياس القبلى القى } & & & \\
\hline & & & $\varepsilon \pm$ & س & $\varepsilon \pm$ & س & & & \\
\hline 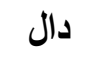 & ๕.70 &.$r V$ & .rr & $\varepsilon . \vee 9$ &. .17 & 0.19 & ثانية & السرعة الانتقالية & \\
\hline 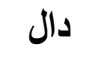 & YI. MI & $\cdot$, Ir & .11 & $r . \cdot v$ & $\cdots v$ & r.ru & 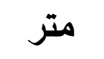 & القوة المميزة بالسرعة & \\
\hline 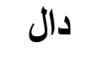 & 9.9. & .11 &. $.1 \mathrm{~V}$ & \urcorner.$\wedge r$ & $\ldots 0$ & $V . \leqslant 1$ & ثانية & الرشاقة & 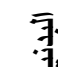 \\
\hline 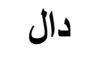 & $7 . \varepsilon r$ & $\vee .91$ & 7.71 & $\vee Y .7 \Lambda$ & $V .0 \leqslant$ & OV.r. & 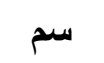 & المرونة & \\
\hline 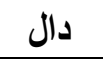 & $r .97$ & $\cdots \varepsilon V$ & .11 & $\varepsilon .+r$ &.$r q$ & $\varepsilon . V Y$ & ثانية & & $\bar{\xi}$ \\
\hline 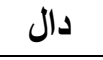 & $0.7 r$ & $1.1 \mathrm{~V}$ & .01 & r.०人 &. $.7 \mathrm{~V}$ & $1 . \leqslant r$ & درجة & & $\bar{\jmath}$ \\
\hline 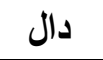 & $\varepsilon . \wedge$. &. .79 & .ro & r.rv & $\cdots \leqslant 1$ & $\varepsilon . .7$ & ثانية & السيطرة ثم الجرى بالكرة & $\$$ \\
\hline دال & $1 r \ldots$ & $1 .+1$ & $\cdots \leqslant 9$ & Y.7V &. .01 & 1.01 & درجة & ثم التمرير & "צ \\
\hline 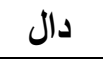 & A.7r &. .01 & $\cdots \wedge$ & r.l $\varepsilon$ & .47 & $r . \leqslant \Lambda$ & ثانية & السيطرة ثم الجرى بالكرة & .9 \\
\hline 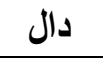 & $v_{.} .$. & 1.10 & $\rightarrow \leqslant 0$ & r.ro & $\cdots 9$. & 1.0. & درجة & ثم التصويب & $\frac{\sqrt[3]{9}}{\sqrt[7]{9}}$ \\
\hline دال & $1 . . \wedge 1$ & $\cdots v 1$ & $\cdot r_{1}$ & $r .79$ &.$r r$ & $\varepsilon . r q$ & ثانية & السيطرة ثم المراوغة ثم & $\overline{7}$ \\
\hline دال & $V . r \leq$ & r... & $.0 Y$ & r.o. & $\cdots v q$ & $1 . \varepsilon Y$ & درجة & التصويب & $\underbrace{2}$ \\
\hline
\end{tabular}

ويتضح من جدول (؟) وجود فروق دالة إحصائياً بين متوسطات القياسين القبلى والبعدى للمجموعة التجريبية

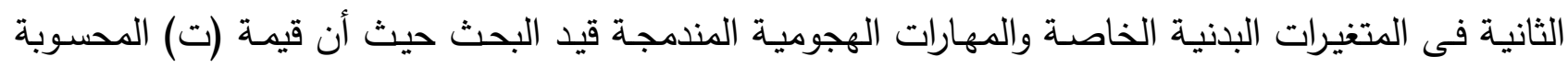

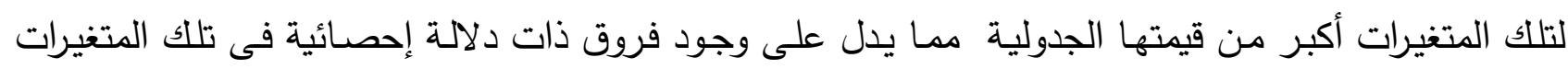

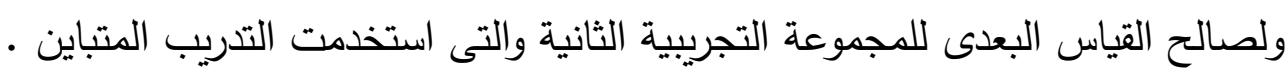




\section{جدول ( ) (•)}

دلالة الفروق الإحصائية بين متوسطات القياسين البعديين فى كلاً من متفيرات الصفات البدنية الخاصة والمهارات الهجومية المندمجة قيد البحث للمجموعتين التجريبيتين الأولى والثانية 1. $=r$ ن

\begin{tabular}{|c|c|c|c|c|c|c|c|c|c|}
\hline \multirow{3}{*}{ مستوى } & \multirow{3}{*}{ قالمحسوبة } & \multirow{3}{*}{ الفتوسطين } & \multicolumn{2}{|c|}{ الثانية (تدريب متباين) التجريبية } & \multicolumn{2}{|c|}{ الألجملى (تدريب متزامن) التجربيبة } & \multirow{2}{*}{ القياس } & \multirow{2}{*}{\multicolumn{2}{|c|}{ الإحصاء }} \\
\hline & & & \multirow{2}{*}{$\frac{\varepsilon \pm}{. r r}$} & \multirow{2}{*}{$\frac{w}{\text { \&.Vq }}$} & \multirow{2}{*}{$\frac{\varepsilon \pm}{\ldots \wedge}$} & \multirow{2}{*}{$\frac{w}{2.9 V}$} & & & \\
\hline & & & & & & & ثانية & السرعة الانتقالية & \\
\hline 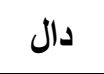 & T.Yo & $\cdots \leqslant r$ & .11 & $r . . v$ &. .19 & r.tr & متر متر & القوة المميزة بالسرعة & \\
\hline 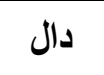 & r.VA & .ro &. $.1 \mathrm{~V}$ & ד.Ar & . rr & v.. 1 & ثانية & الرشاقة & $\overline{7}$ \\
\hline دال - & $\{.71$ & 1.7. & 7.71 & Vr.TA & r.^० & Tr.A. & 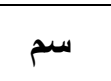 & المرونة & \\
\hline دال & $\mathrm{r.IV}$ &.$r q$ &. .11 & $\varepsilon \ldots r$ &..$\mu \Lambda$ & \&. $\leqslant 1$ & ثانية & & \\
\hline دال & r.01 &. $.7 V$ &. .01 & Y.OA & 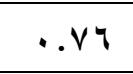 & $1.9 r$ & درجة & & \\
\hline 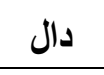 & A.Vr & $1 . . \varepsilon$ & .ro & $r . r V$ & 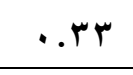 & $\{. \leqslant 1$ & ثانية & السيطرة ثم الجرى بالكرة & \\
\hline 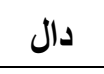 & $r .91$ &..$\wedge \wedge$ & $\cdot . \leqslant 9$ & T.TV &. .01 & 1.19 & درجة & ثم التمرير & \\
\hline دال & $r . \leqslant 7$ &. $.1 r$ & $\cdots \wedge$ & $r .1 \leq$ & .90 & r.rt & ثانية & السيطرة ثم الجرى بالكرة & $\sqrt[3]{7}$ \\
\hline دال & $0 . \leqslant r$ & $1 \ldots$ & $\cdots \leqslant 0$ & r.ro & $\cdots \leqslant 0$ & T.YO & درجة & ثم التصويب & \\
\hline 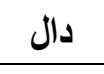 & $\Lambda .1 \mathrm{r}$ & .7 &.$r_{1}$ & $r .79$ & $. .1 \leqslant$ & $\varepsilon . r q$ & ثانية & السيطرة ثم المراوغة ثث & .7 \\
\hline دال & $\varepsilon . \wedge \varepsilon$ & $1.1 \mathrm{~V}$ &. $.0 r$ & r.o. &. .70 & T.rT & درجة & التصويب & \\
\hline
\end{tabular}

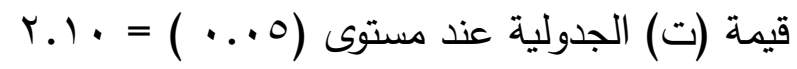

ويتضح من جدول (0) وجود فروق دالة إحصائياً بين متوسطات القياسين البعديين للمجموعة التجريبية الأولى والثانية فى المتغيرات البدنية الخاصة والمهارات الهجومية المندمجة قيد البحث أن قيمة (ت) المحسوبة

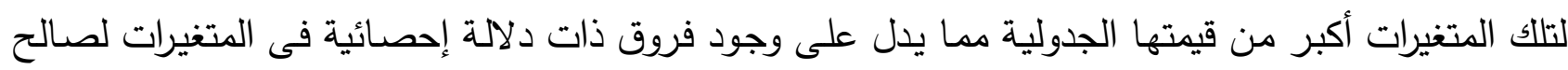

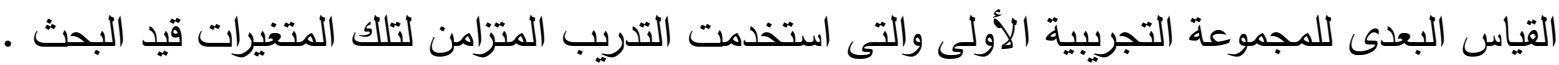
ثانياً : مناقثة النتائج :-

وللتحقق من صحة الفرض الأول قام الباحث بمقارنـة نتائج الفروق بين متوسطات القياسـات القبلية والبعدية في اختبارات بعض الصفات البدنية الخاصة قيد البحث (السرعة الإنتقالية - القوة المميزة بالسرعة -

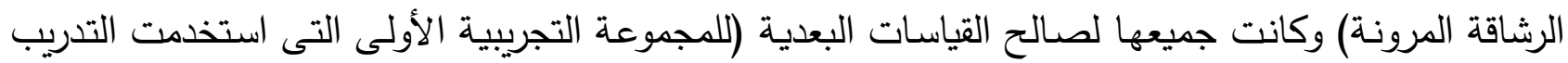

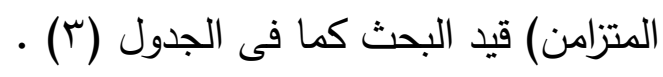


ويرجح الباحث التحسن فى السرعة الإنتقالية لعينة البحث للمجوعة التجريبية الأولى إلى أن برنامج التدريب المتزامن أدى إلى تحسن القوة القصوى والذى أثر على تحسن السرعة الأمر الذى أدى إلى تحسن عملية

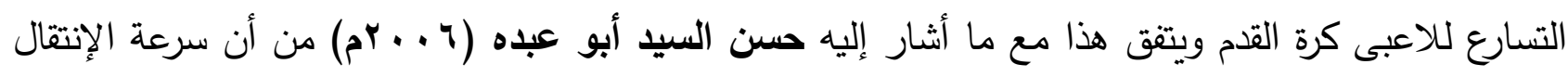

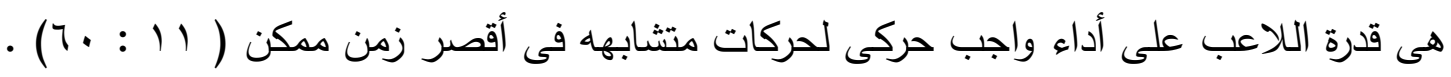
ويعزى الباحث التحسن فى السرعة الإنتقالية إلى إستخدام الباحث التدريبات بالكرة وبدون كرة بطريقة

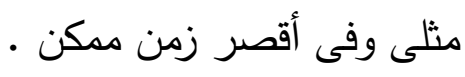
كما يرجح الباحث أيضاً التحسن فى القوة المميزة بالسرعة كأحد عناصر اللياقة البننية الخاصة قيد

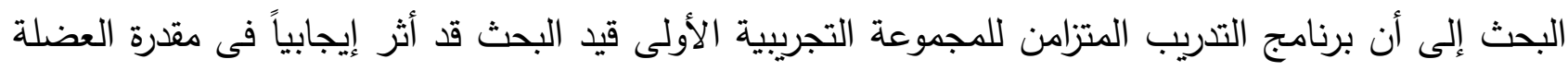

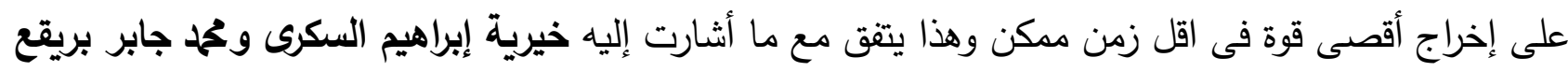

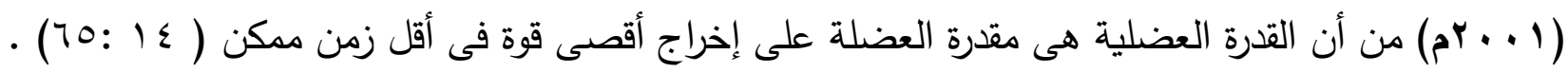
ويعزى الباحث هذا التحسن فى القدرة العضلية عن طريق التغلب على المقاومات بانقباضات عضلية

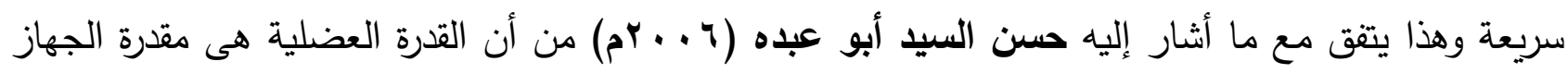

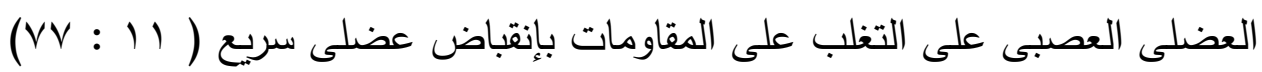
ويؤكد الباحث على أن هذا التحسن يرجع إلى حسن إختيار التمرينات المشابهه للأداء سواء كانت بالكرة أو بدونها وحسن تقنين برنامج التدريب المتزامن والأحمال التدريبية وطرق التدريب المناسبة وفترات الراحة البينية.

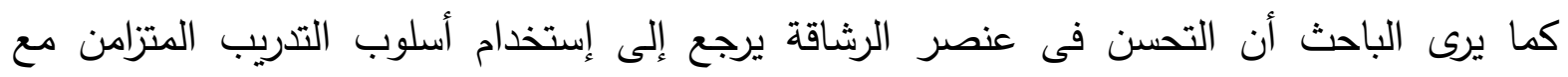

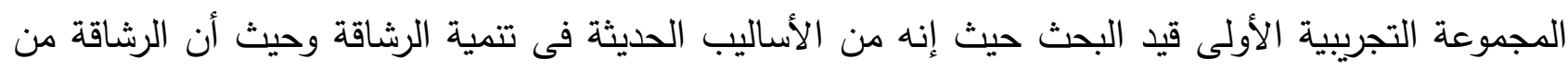

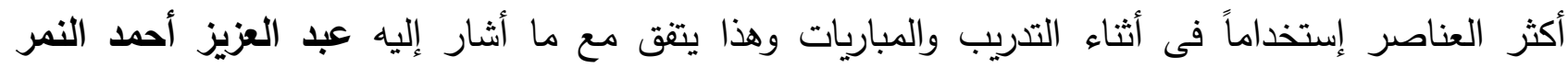

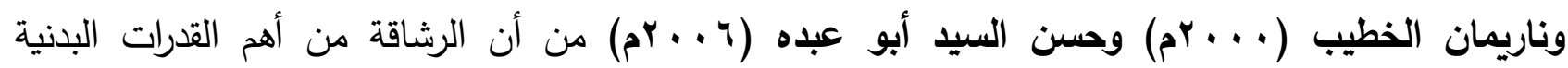

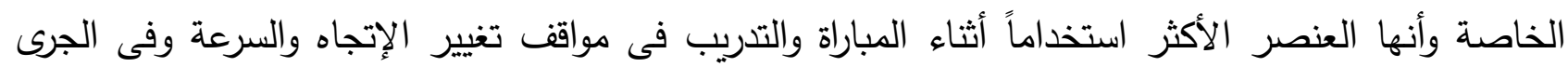
سواء بالكرة أو بدونها وفى الدحاورة والمهاجمة وضرب الكرة بالرأس والسيطرة على الكرة والتصويب مع الإقتصاد التهاد

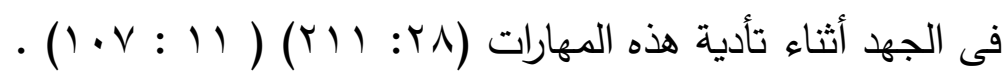
كما يرجح الباحث هذا التحسن إلى إستمرار تدريبات الرشاقة على مدار الموسم التدريبى والتركيز عليها فى فترة

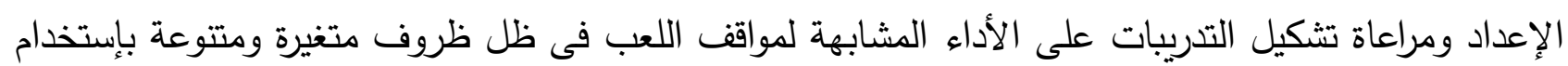

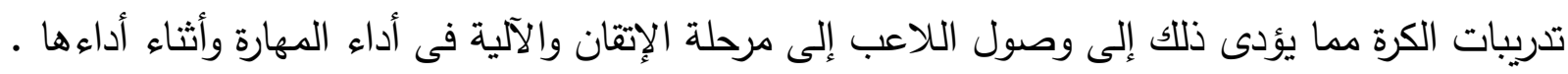
ويعزى الباحث التحسن فى المرونة إلى أن برنامج التدريب المتزامن كان تأثيره واضحاً فى جعل اللاعب

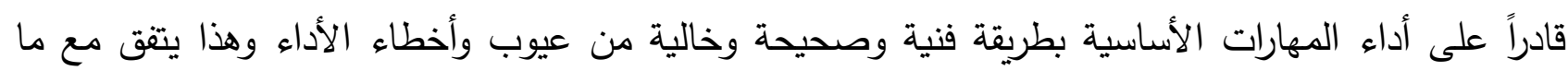

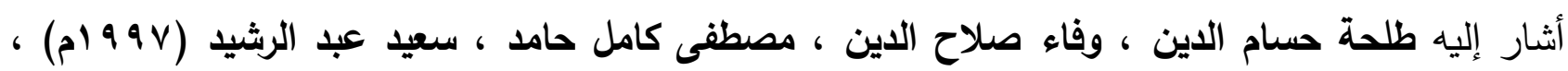




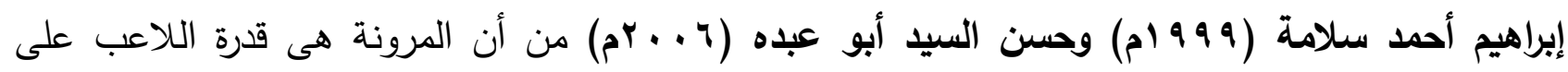
إنجاز المهارات أو أداء الحركات المختلفة بمدى حركى واسع وبحرية وفى إتجاهات معينة طبقاً لمتطلبات الأداء

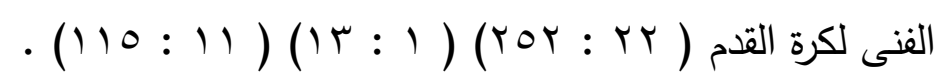

وللتحقق أيضاً من صحة الفرض أيضاً قام الباحث بمقارنة نتائج الفروق بين متوسطات القياسات القبلية والبعدية للمهارات الهجومية المندمجة قيد البحث ( السيطرة ثم التمرير - السيطرة ثم الجرى بالكرة ثم التمرير -

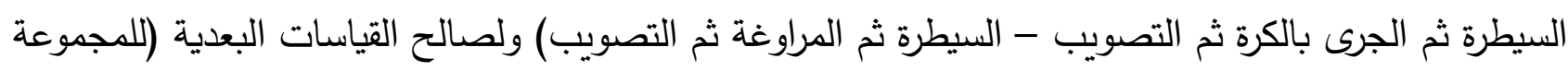
التجريبية الأولى التى استخدمت التدريب المتزامن) قيد البحث كما فى جدول (r) ـ ويعزى الباحث التحسن فى المهارات المندمجة الهجومية قيد البحث إلى إستخدام برنامج التدريب

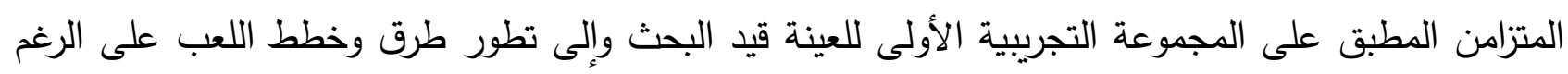

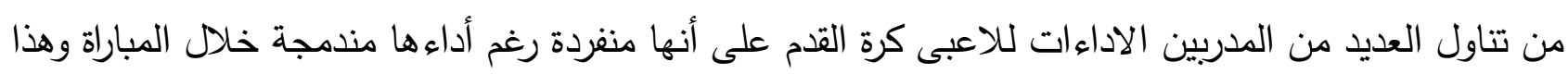

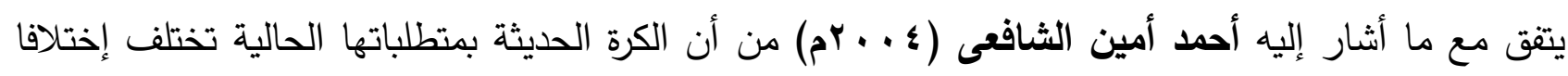

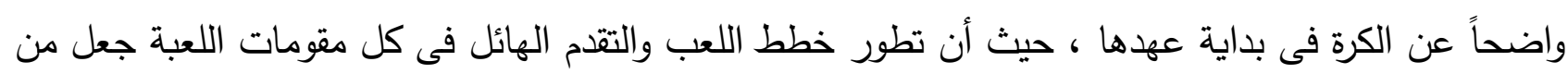

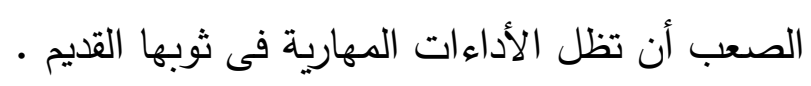

ويؤكد الباحث على أن هذا التحسن والتطور فى مستوى الأداء نتيجة للتطور الحادث فى سرعة الأداء وخطط اللعب حيث انه لا يمكن للاعب إتقان واجباته داخل الملعب وخاصة الواجبات الخططية بدون إتقان هذه

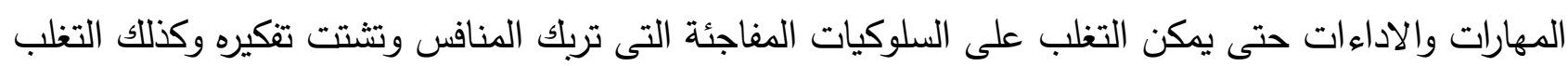

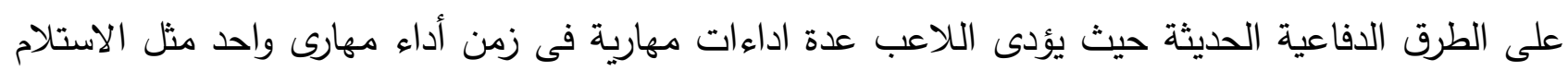

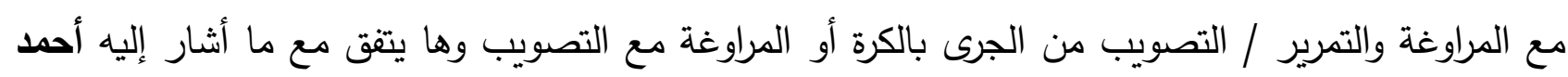

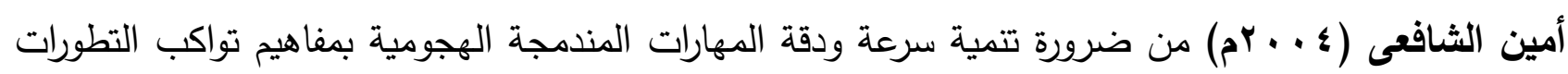

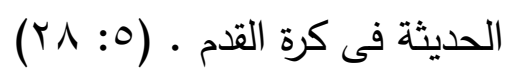

كما يعزى الباحث التحسن فى مستوى المهارات المندمجة الهجومية قيد البحث إلى إستخدام برنامج

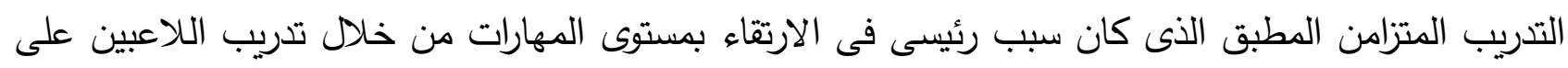

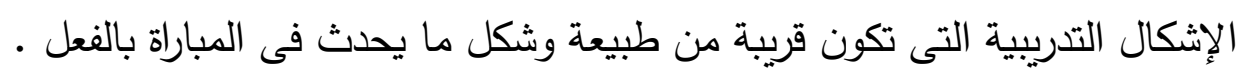
كما يؤكد الباحث على مدى إرتباط تتمية الصفات البدنية بتطوير مستوى المهارات المندمجة الهجومية

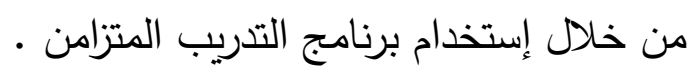

وكما يتضح من جدول (†) وجود فروق ذات دلالة إحصائية بين القياس القبلي والبعدي للمجموعة

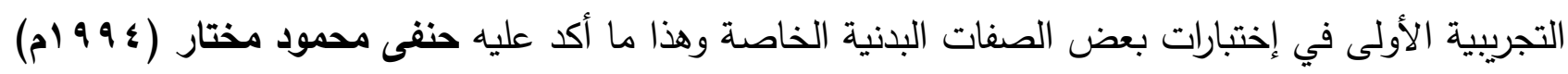

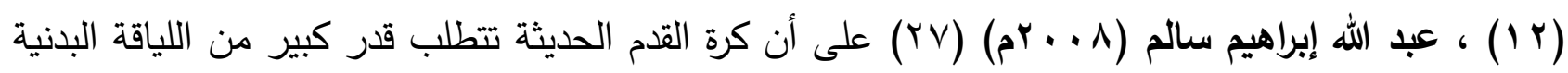

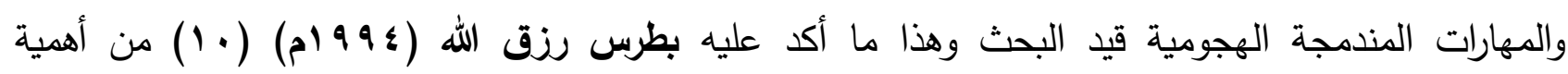


المهارات المندمجة الهجومية للاعبى كرة القدم وظهر ذلك من خلال القياسات البعدية (للمجموعة التجريبية

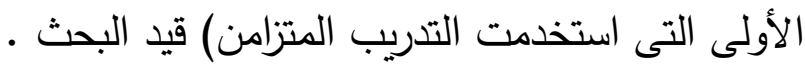

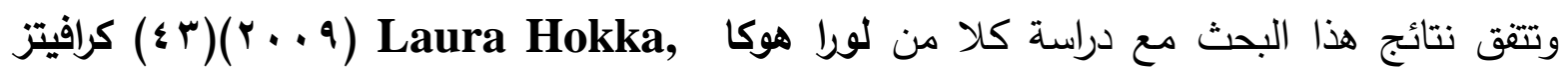

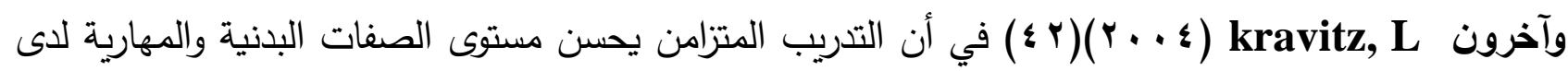
ممارسي الأنشطة الرياضية وبذلك يكون قد تحقق الفرض الأول . وللتحقق أيضاً من صحة الفرض الثانى قام الباحث بمقارنة نتائج الفروق بين متوسطات القياسات القبلية

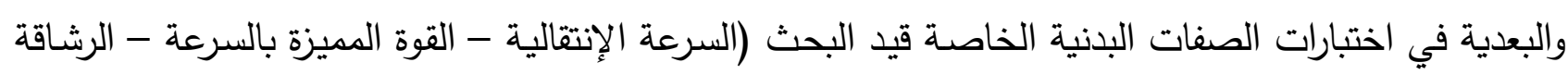

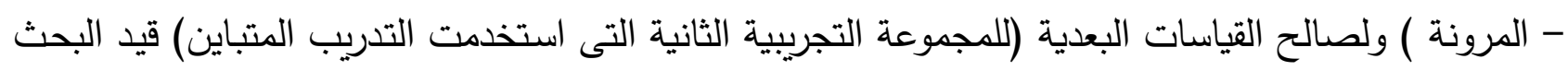

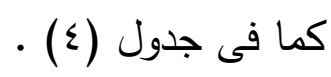

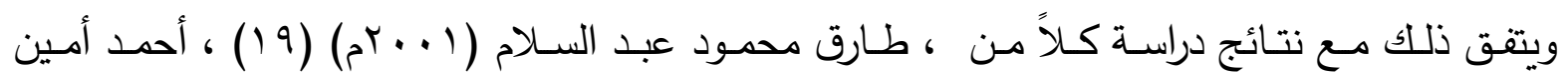

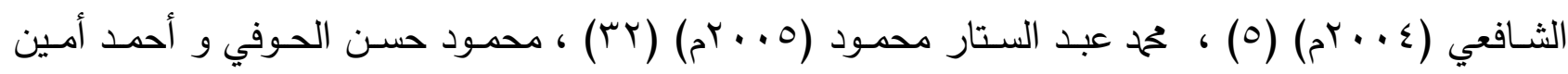

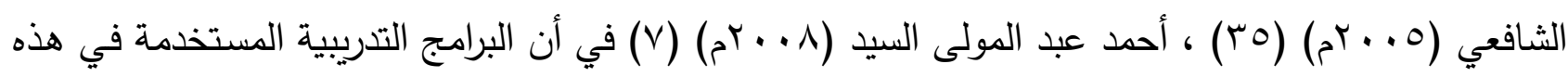

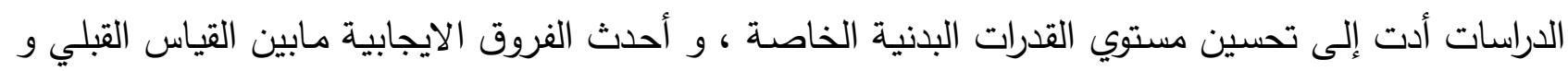

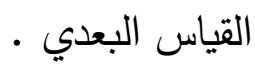

ويعزى الباحث التحسن فى تلك المتغيرات البدنية قيد البحث إلى حسن إختيار التمرينات المناسبة وكذلك

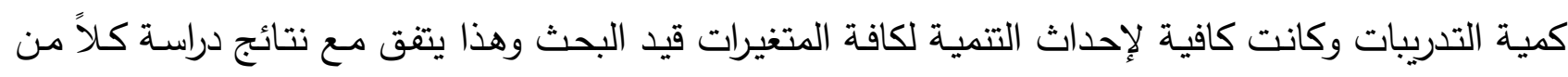

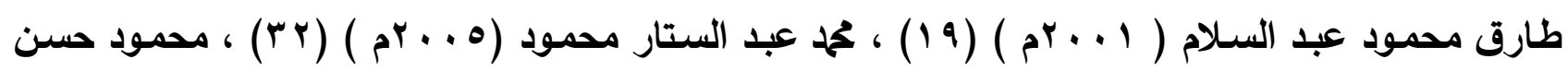

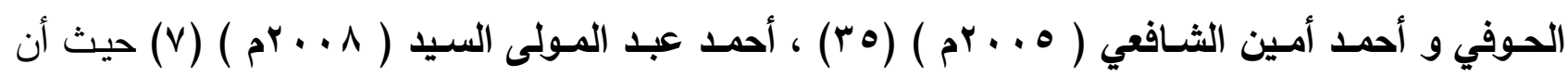

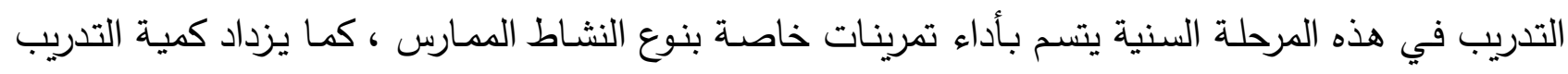

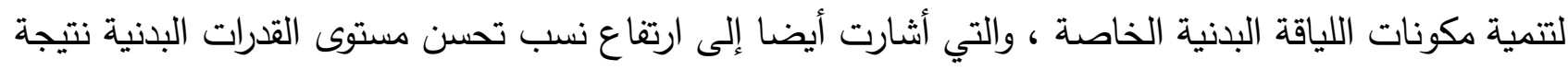
تطبيق البرامج التدريبية المستخدمة .

ويعزى الباحث هذا التحسن إلى حسن اختيار محتوى الوحدات التدريبية للبرنامج التدريبي والذي تميز

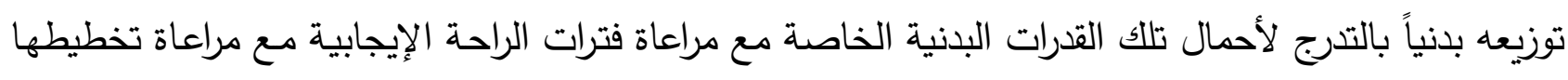
داخل الوحدات التدريبية بشكل جيد .. الأمر الذي أدى إلى هذا التحسن الملحوظ في مستوى أداء القدرات البدنية

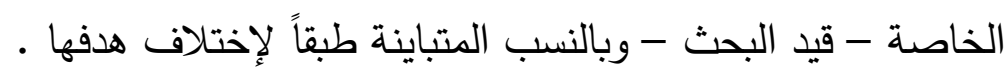

وللتحقق من صحة الفرض قام الباحث بمقارنة نتائج الفروق بين متوسطات القياسات القبلية والبعدية

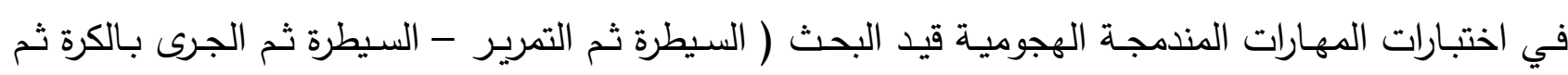
التمرير - السيطرة ثم الجرى بالكرة ثم التصويب - السيطرة ثم المراوغة ثم التصويب) ولصالح القياسات البعدية

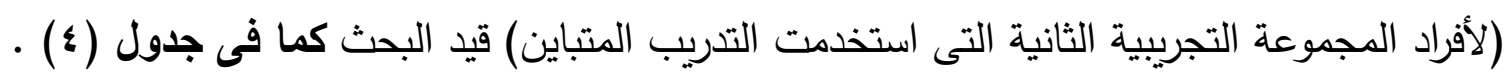


ويعزى الباحث التحسن فى هذه المتغيرات إلى إستخدام برنامج التدريب المتباين المقترح والمطبق

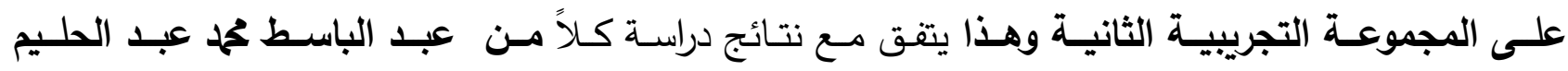

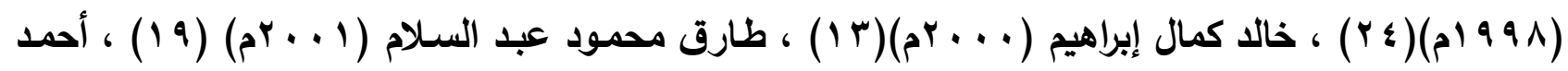

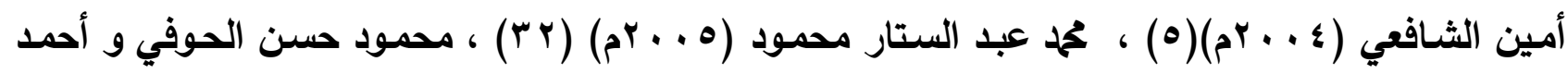

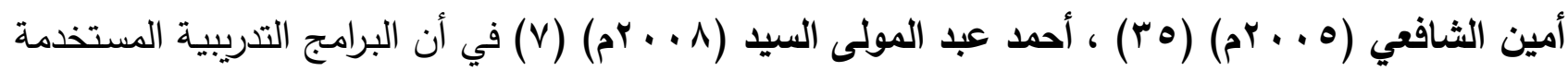

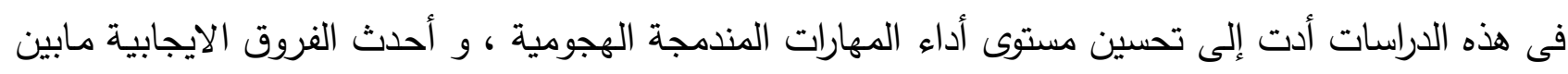

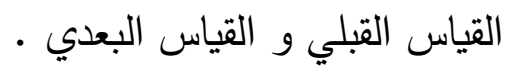

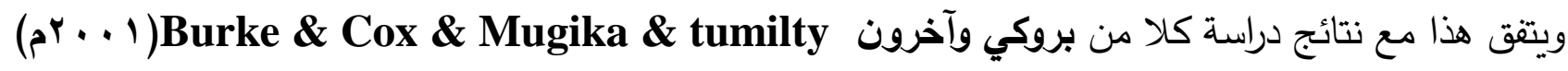

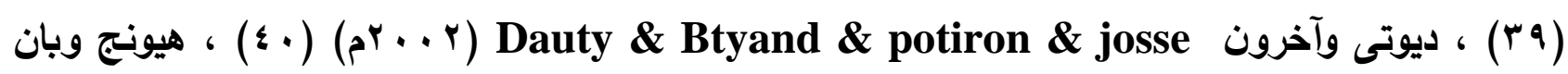
Huang \& pan

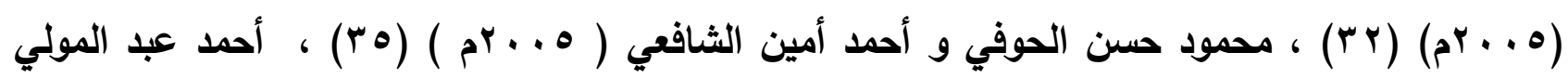

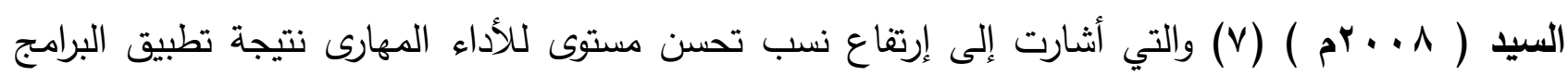
التدريبية المقترحة .

ويعزى الباحث هذا التحسن الحادث لسرعة ودقة الأداء المهارى المندمج قيد البحث خـلال

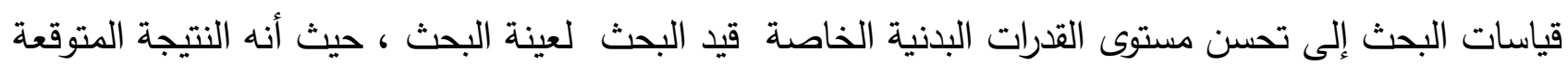

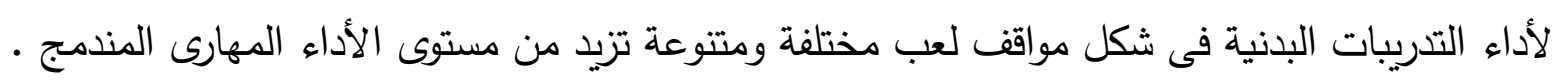
ويتضح من جدول (§) وجود فروق ذات دلالة إحصائية بين القياس القبلي والبعدي للمجموعة التجريبية

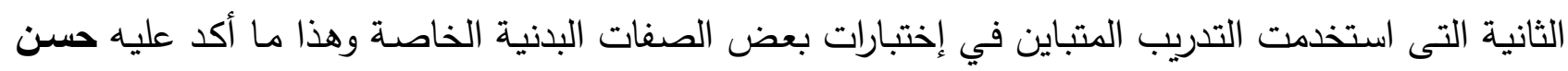

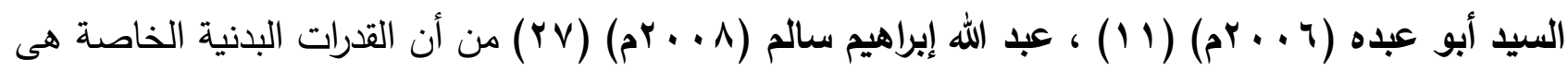

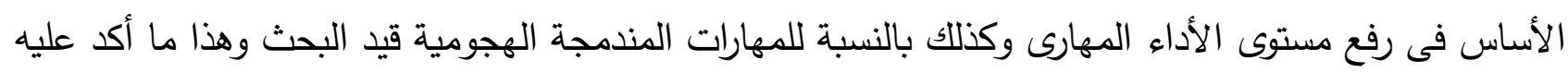

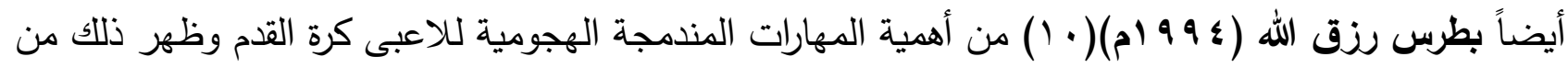

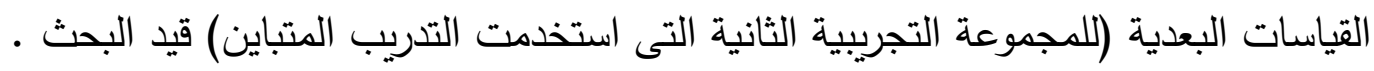

ويرى الباحث أن البرنامج التدريبي المقترح بإستخدام التدريب المتباين أدي إلي تحسن في القدرات البدنية

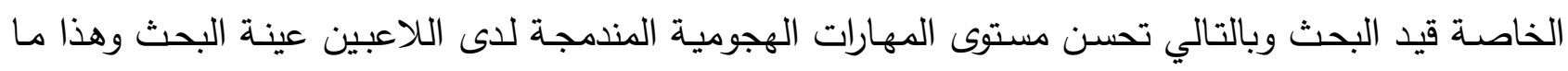

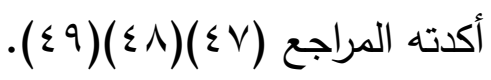

كما يؤكد الباحث على أن تتمية القدرات البدنية الخاصة قيد البحث أدت إلى تحسين مستوى المهارات الهجومية المندمجة قيد البحث وذللك لتطبيق برنامج التدريب المتباين المقنن وحسن إختيار التدريبات سواء كانت 
بالكرة أو بدون كرة وطرق التدريب وتشكيل الحمل وفترات الراحة البينية بصورة جيدة داخل محتوى البرنامج

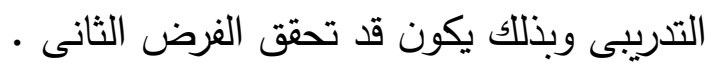

وللتحقق من صحة الفرض الثالث قام الباحث بمقارنة نتائج الفروق بين متوسطات القياسات البعدية

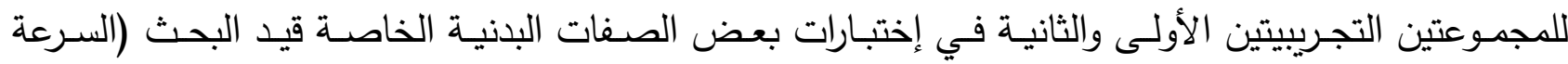

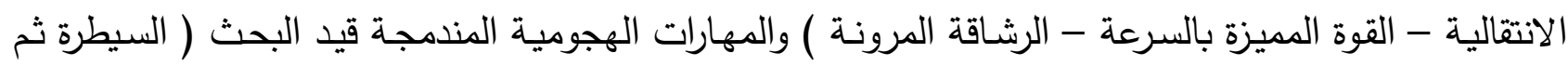

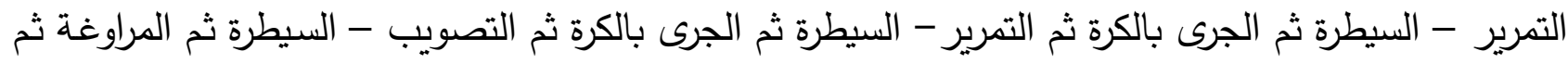

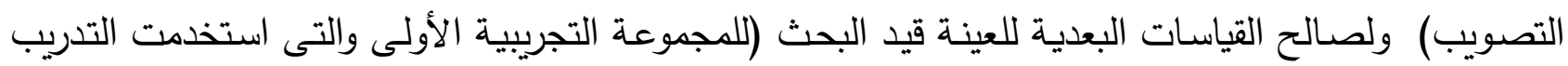

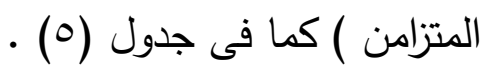

ويعزى الباحث هذا التحسن إلى حسن إختيار برامج التدريب المطبقة على المجموعتين التجريبيتين الأولى

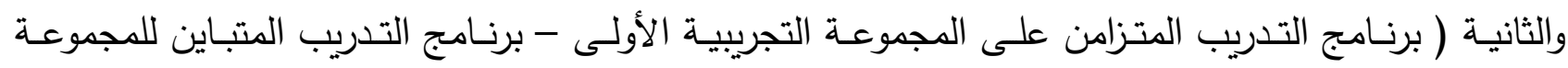

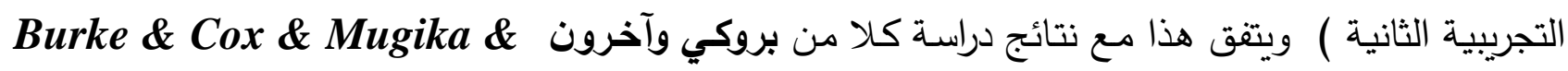
(r) Dauty \& Btyand \& potiron \& josse tumilty

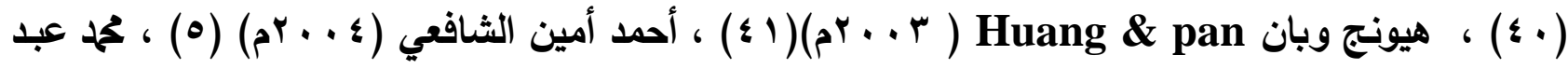

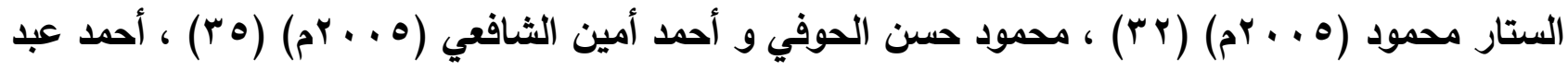

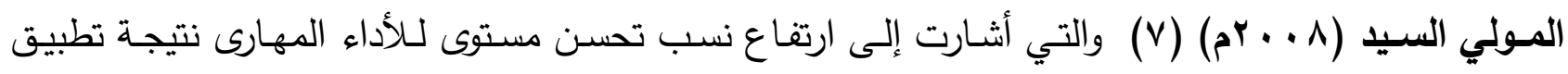
البرامج التدريبية المقترحة .

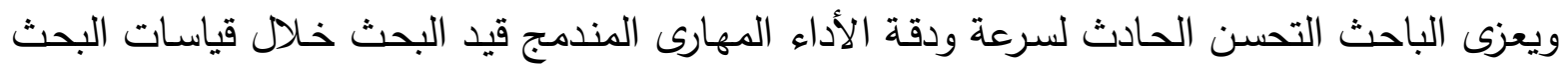
إلى تحسن مستوى القدرات البدنية الخاصة قيد البحث لعينة البحث ، حيث أن النتيجة المتوقعة لأداء التدريبات البدنية فى شكل مواقف لعب مختلفة ومتتوعة تزيد من مستوى الأداء المهارى المندمج . كما يرجح الباحث هذا التحسن المرتفع لمهارة السيطرة ثم التمرير نتيجة لبساطة تركيب هذه المهارة حيث

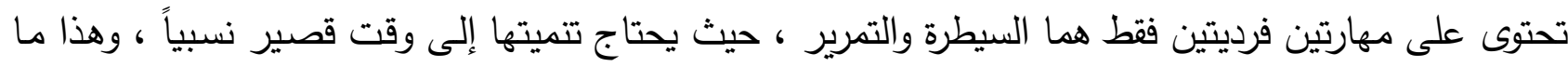

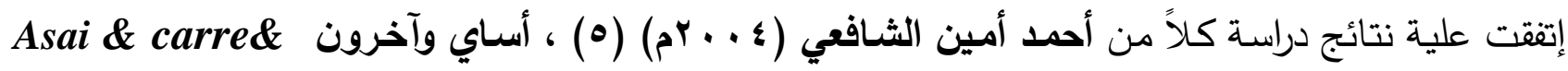
Akatsaka\& \& Haak

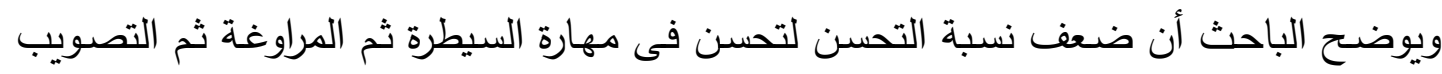

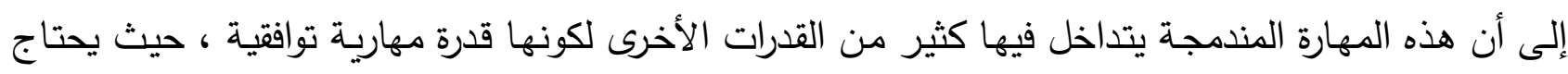

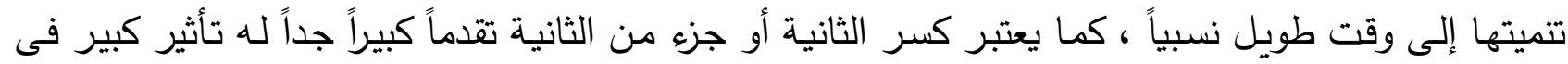

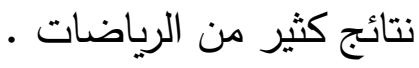


ويرى الباحث أن البرنامج التدريبي المقترح باستخدام التدريب المتزامن والتدريب المتباين أدي إلي تحسن

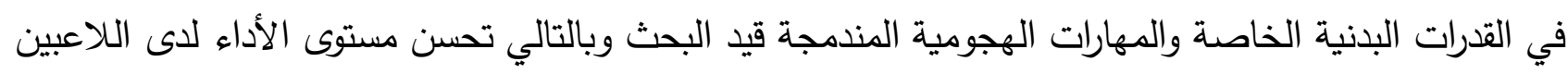
عينة البحث ولكن كانت نسبة التحسن أكبر للمجموعة التجريبية الأولى التى إستخدمت أسلوب التدريب المتزامن

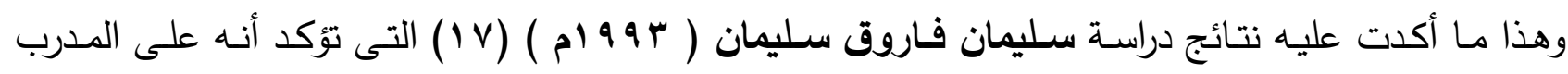

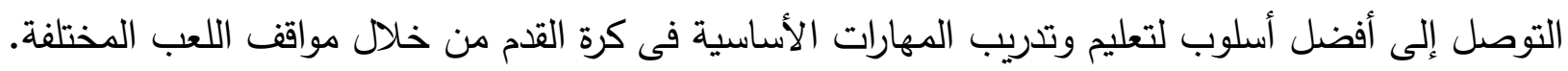
وهذا أشار إلية كرافيتز Kravitz, ( . . . rم) من التأكيد المستمر والمتزايد تجاه الوصول إلى الإنجاز

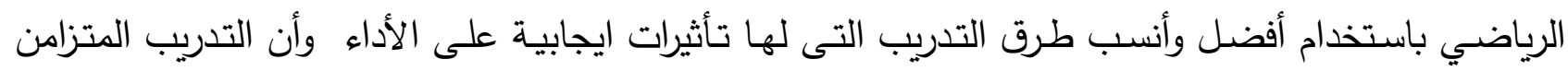

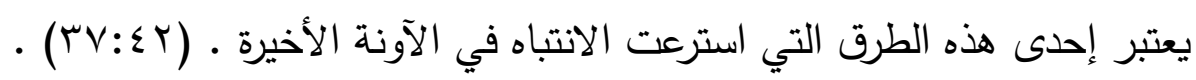

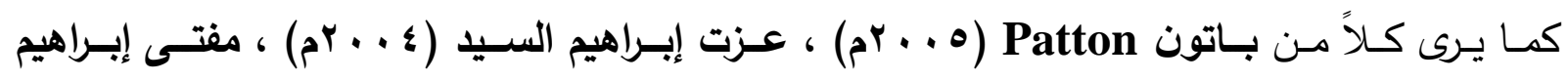

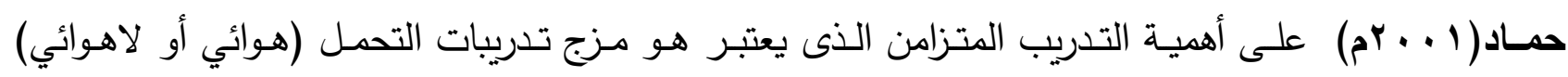
- (Tr:rv) (rt:rq) (ArT:ST)

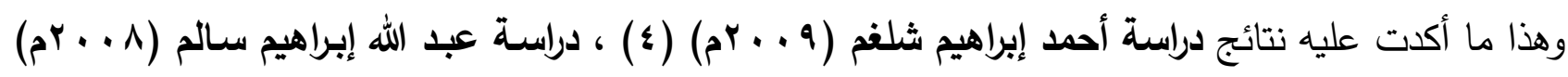

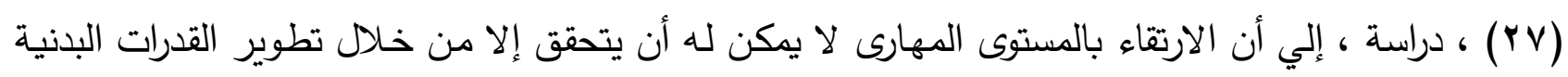

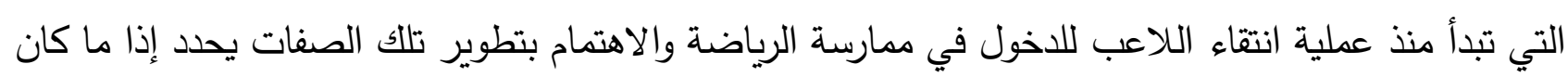
اللاعب سوف يستمر في ممارسة اللعبة أو لا، حتى يتمكن من ملاحقة تطور المستوى المهارى للاعبين الذي الذياض يتغير كل بطولة.

وتؤكد نتائج هذه الدراسة على أن التحسن في المستوي المهارى يتاسب تتاسب طرديا مع تحسن القرات

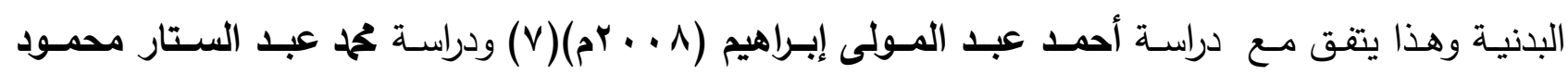

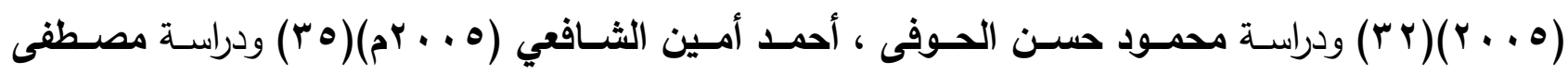

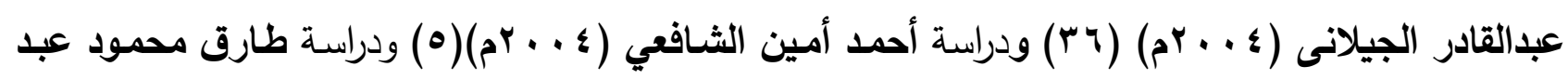

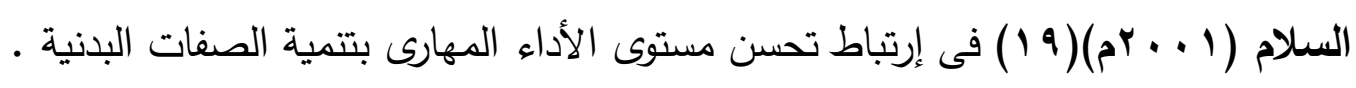

ويعزى الباحث التحسن فى مستوى المهارات المندمجة الهجومية قيد البحث نتيجة تتمية الصفات البدنية

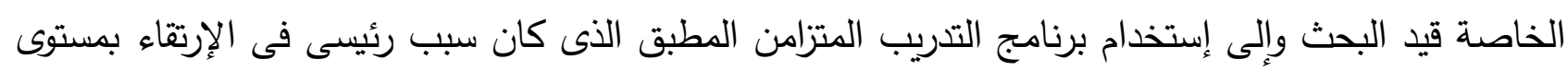

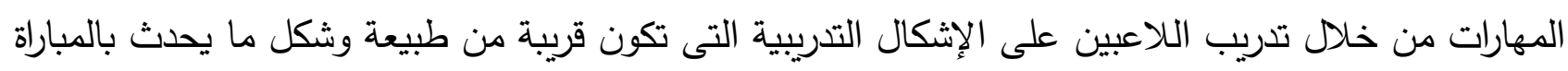
بالفعل .

كما يؤكد الباحث على أن التحسن فى الصفات البدنية الخاصة قيد البحث نتيجة لإستخدام التمرينات

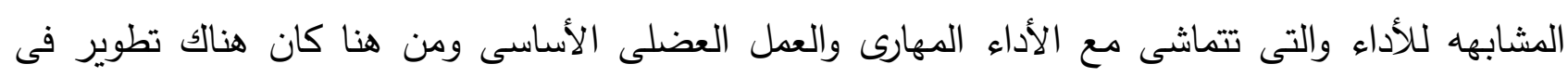

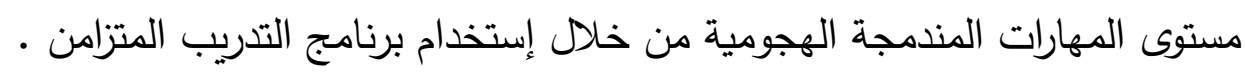


أولاً : الاستنتاجات : والنتائج التى تم التوصل إليها هى :-

( (1) ويتضح من جدول (r) وجود فروق دالة احصائياً فى القياسات القبلية والبعدية لأفراد المجموعة التجريبية

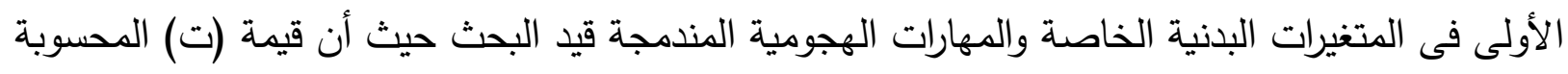
لتلك المتغيرات أكبر من قيمتها الجدولية مما يدل على وجود فروق ذات دلالة إحصائية فى المتغيرات البدنية

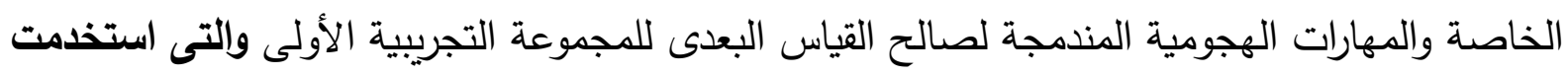

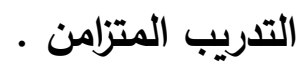

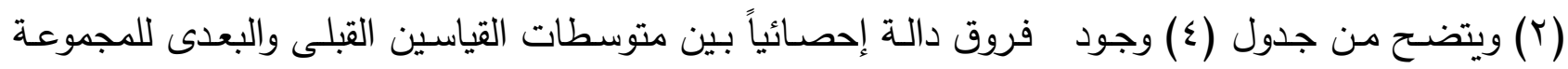

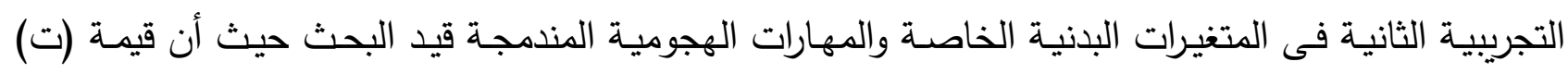

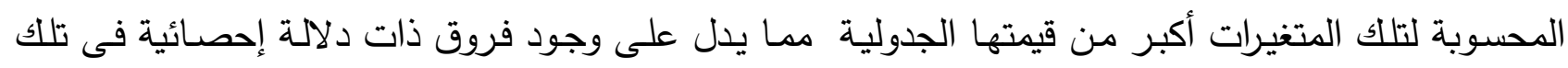

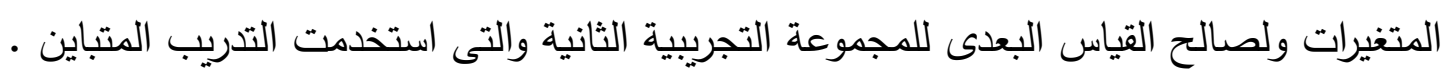

(r) ويتضح من جدول (0) وجود فروق دالة إحصائياً بين متوسطات القياسين البعديين للمجموعة التجريبية

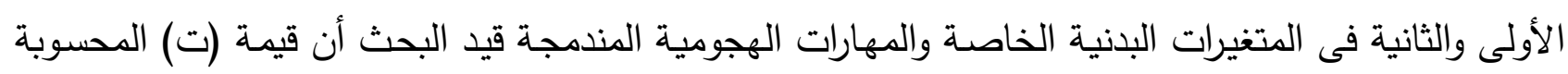

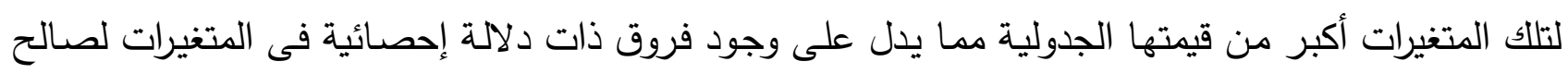

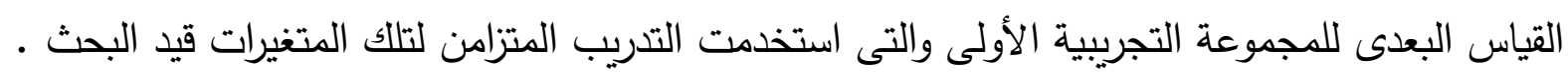
(؛) برنامج أسلوبى التدريب المتزامن والمتباين المقترحين قد أدو إلى تحسن في مستوى بعض المتغيرات البدنية

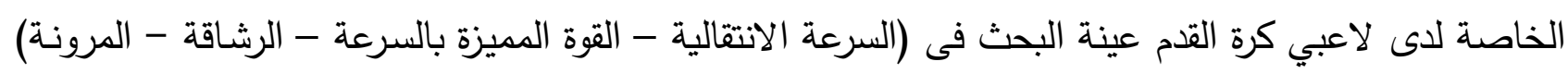
للى مجموعة البحث التجريبية الأولى والثانية ولكن كانت نسبة التحسن أكبر بالنسبة لبرنامج التدريب المتزامن

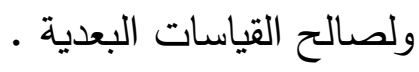

(0) برنامج أسلوبى التدريب المتزامن والمتباين المقترحين قد أدو إلى تحسن في مستوى المهارات المندمجة

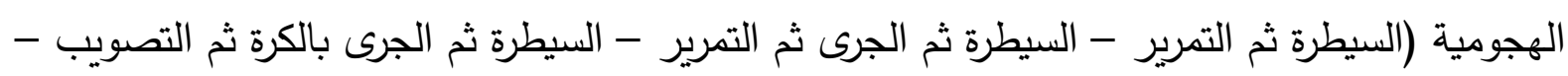

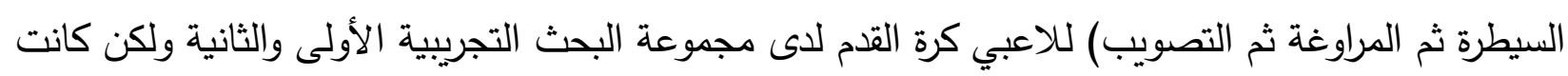
نسبة التحسن أكبر بالنسبة لبرنامج التدريب المتزامن ولصالح القياسات البعدية . ثانياُ : التوصيات

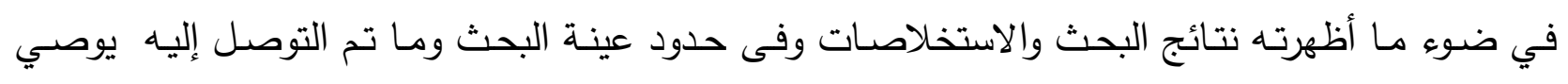

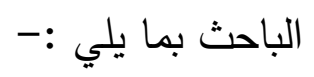

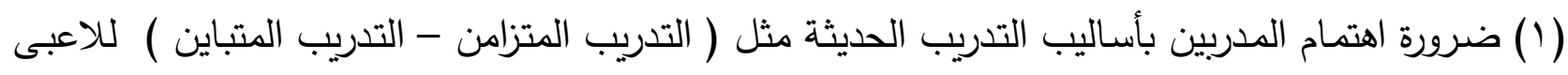
كرة القدم وتثكيلها فى الوحدات التدريبية ووضعها في تدريبات متدرجة الصعوبة من حيث التركيب بما يجعلها أكثر تشويقاً وتثابهاً لما يحدث في المباريات المدات التربية ورضعات 
(Y) تطبيق الأسس والمبادئ العلية في بناء وتصميم البرامج التدريبية الخاصة بالارتقاء بالتدريبات التزامنية

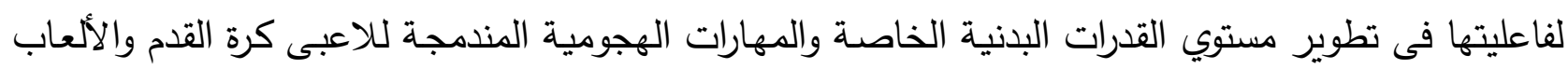
الأخرى وعلى عينات وصفات بدنية ومهارية مختلفة . (r) استخدام الأساليب والتقنيات العلمية الحديثة فى تعليم وتعلم وتدريب كرة القدم . 


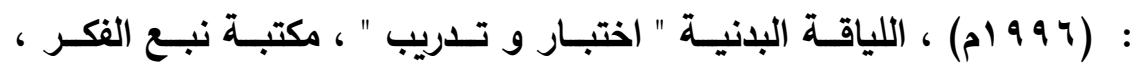

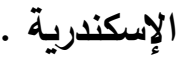

r. أبو العلا أحمد عبد الفتاح (999 19)، فسيولوجيا التدريب في كرة القدم ، دار الفكر العربي ، القاهرة .

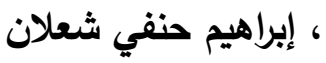

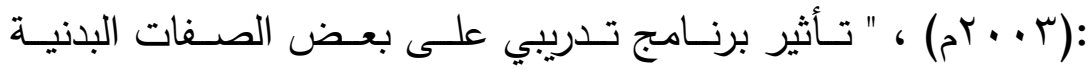

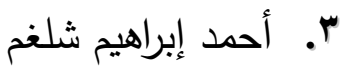
الخاصة والمهارية لناشئات كرة القدم "، رسالة ماجستير غير منشورة،كلية

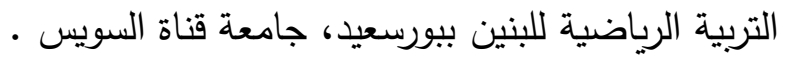

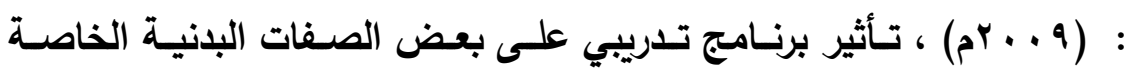

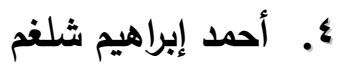

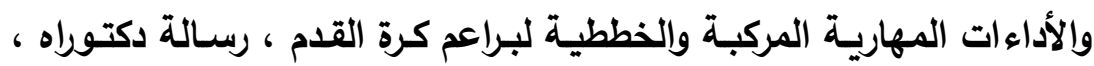

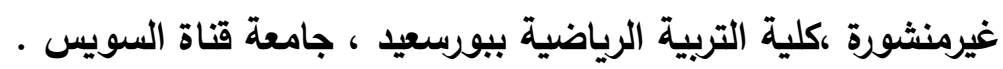

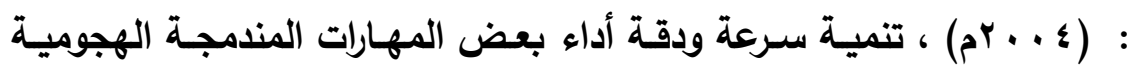

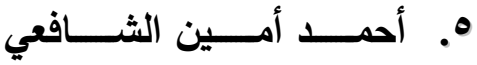

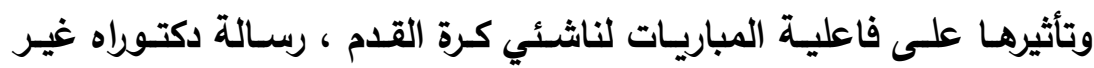
منشوره ، كلية التربية الرياضية بالسادات ، جامعة المنوفية .

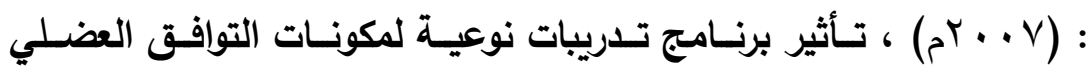
T. - (إسلام مسعد علي محمود

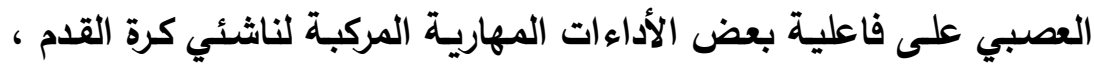

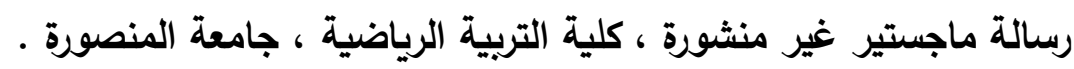

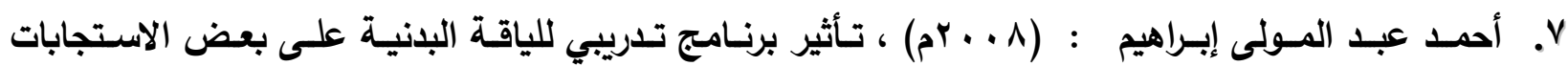

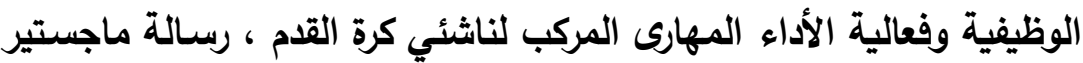
غير منثورة ، كلية التربية الرياضية ، جامعة المنصورة .

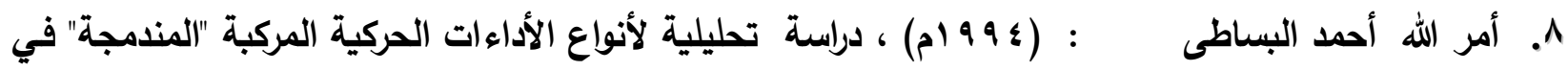
بعض الألعاب الجماعية خلال المباراة ، رسالة دكتوراه غير منشورة ، كلية التربية الرياضية للبنين ، جامعة الإسكندرية .

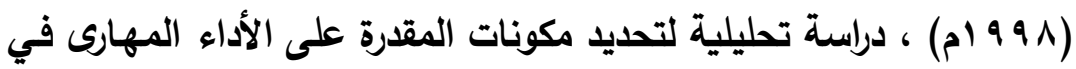
9. - أمر الله أحمد البساطى كرة القدم ، المجلة العلمية ، " نظريات وتطبيقات " ، كلية التربية الرياضية لالبنين ، جامعة الإسكندرية .

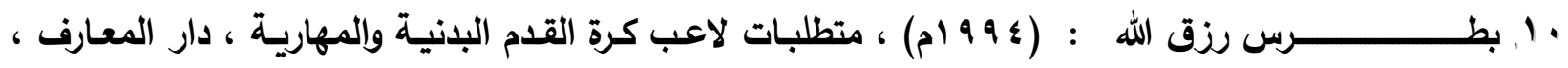

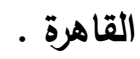

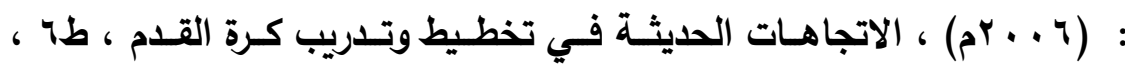

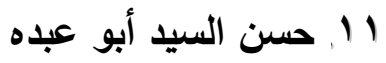
مطبعة الإثعاع الفنية ، الإسكندرية .

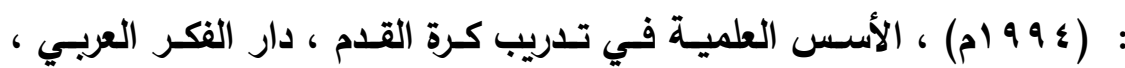

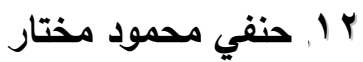

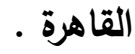

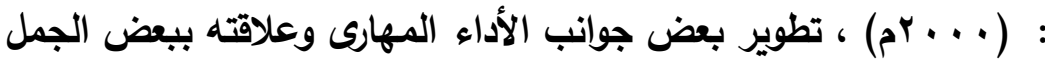

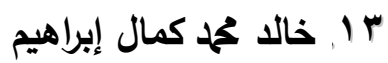


الخططية للاعبي كرة القدم الناشئين تحت 9 سنة خلال فترة الإعداد ،

رسالة ماجستير غير منشورة ، كلية التربية الرياضية للبنين ، جامعة حلته

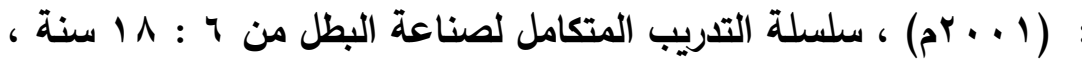
الجزء الثاني ، منشأة المعارف ، الإسكندرية . ع ا بيرية إبراهيم السكري ، محمد جابر بريقع ل : 99 ( م) ، أساسيات كرة القدم ، ط r ب، دار عالم المعرفة ، القاهرة . 10 1 محم عبده صالح ، مفتي إبراهيم حماد

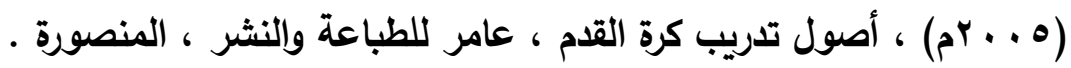
17 19 19

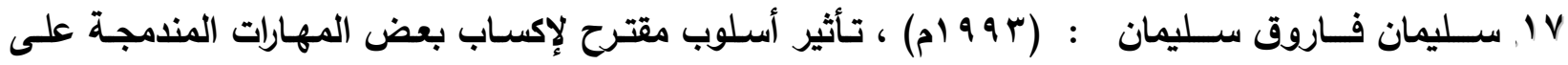
مستوى الأداء الفنـي لناشئي كرة القدم ، رسـالة ماجستير غير منشـورة ،

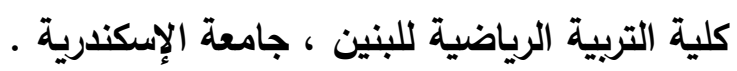

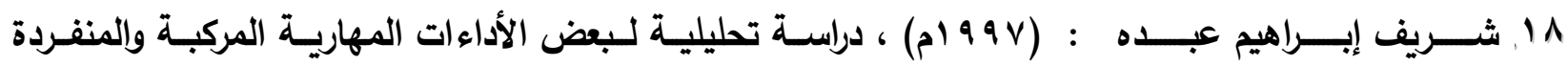
وعلاقتها بنتائج مباريات كأس العالم ه9 99 ام لناشئين تعت V V سنة في

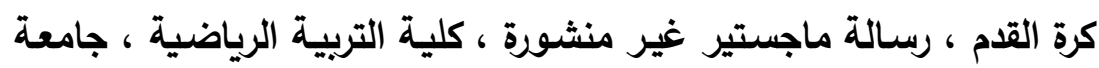

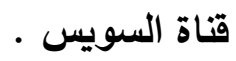

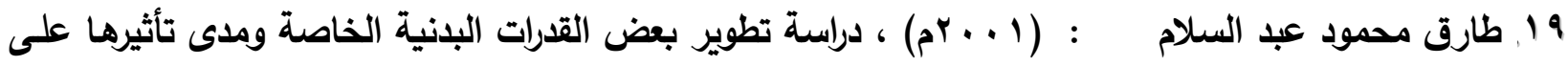
تحسين مستوى الأداء المهارى لناشئي كرة القدم ، رسـالة ماجستير غير

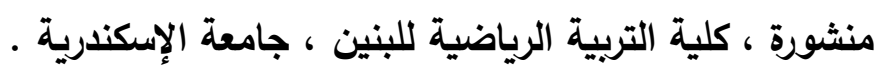

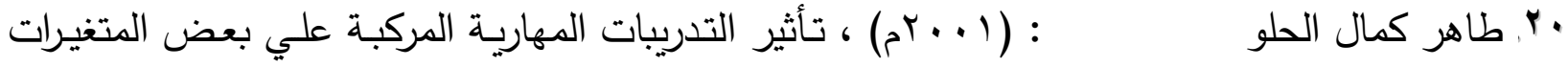
الفسيولوجية ومستوي الأداء المهارى لناشئي كرة القدم ، رسالة ماجستير غير منشورة ككلية التربية الرياضية بورسعيد ، جامعة قناة السويس •

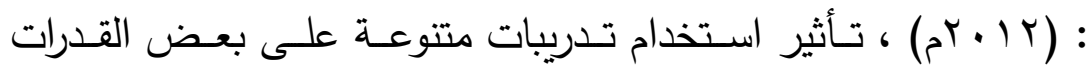

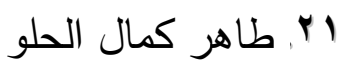
التوافقيـة وأداء المهارات المركبة لبـراعم كرة القدم ، رسـالة دكتوراة غير منشورة ، كلية التربية الرياضية بورسعيد ، جامعة قناة السويس •

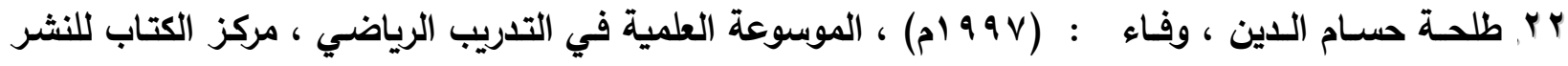

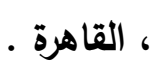

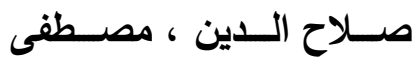
كامـل حامسـ ، سـعيد عبــ

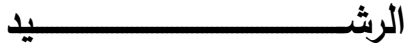

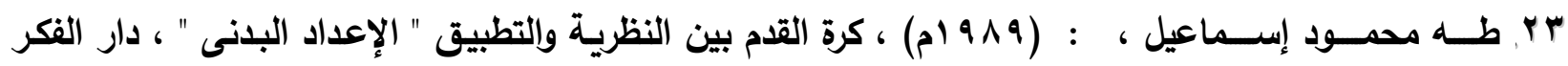
عــرو علـى أبـو المجـــ، العربي ، القاهرة . 


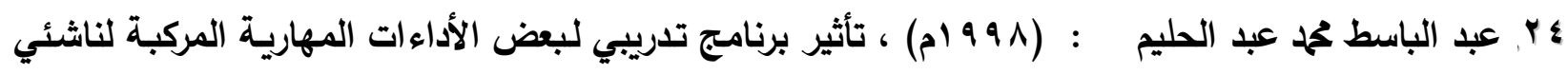

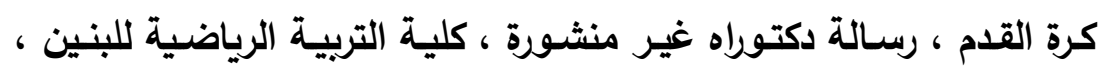

\section{جامعة الإسكندرية .}

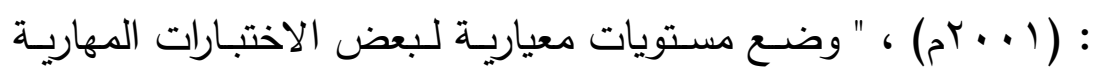

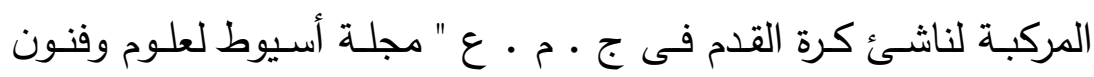

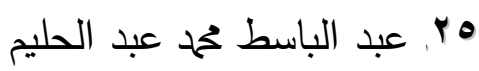

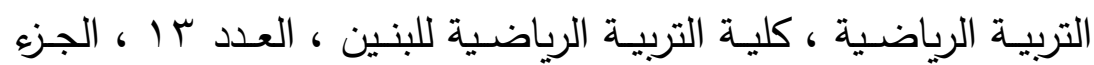

$$
\text { الأول ، جامعة أسيوط. }
$$

: (9 . . ب م) ، تأثير تتمية بعض القدرات التوافقية على بعض المهارات Yr. هيثم عادل عبد البصير المركبـة لبـراعم كرة القدم ، رسـالة دكتوراه غيـر منشـورة ، كليـة التربيـة الرياضية ببورسعيد ، جامعة قناة السويس .

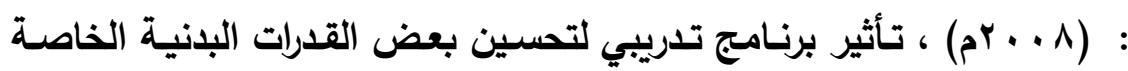
، - مادل إبراهيم عمر

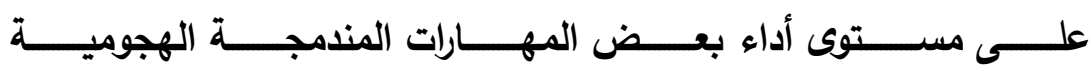
للدى ناشئي كرة القدم ، رسـالة ماجستير، كليـة التربية الرياضية ، جامعة طنطا

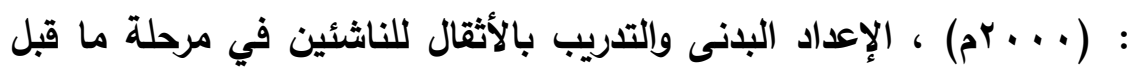

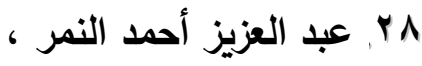

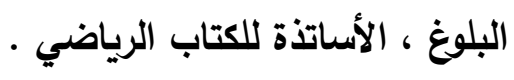
ناريمان الخطيب

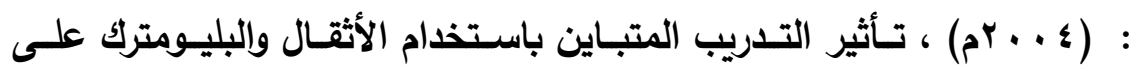
q ب عزت إبراهيم السيد بعض القدرات البدنيـة الخاصـة والمستوى الرقــي للاعبـي الوثب الطويـل، رسالة دكتوراه ، كلية التربية الرياضية، جامعة طنطا ـ

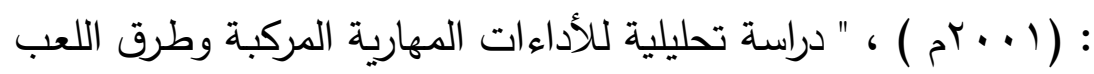

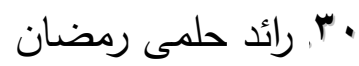
وأثرها على نتائج المباريـات فى كأس العالم الأمم الأفريقيـة لكرة القدم

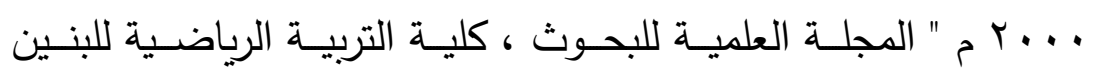

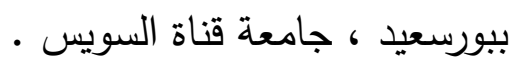

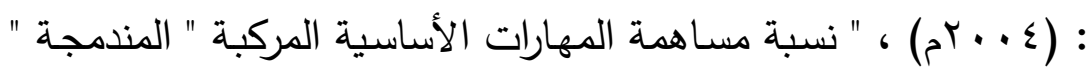
ابr محمد إبراهيم سلطان على أداء بعض المبـادئ الخططيـة لناشـئ كرة القدم " مجلـة نظريـات

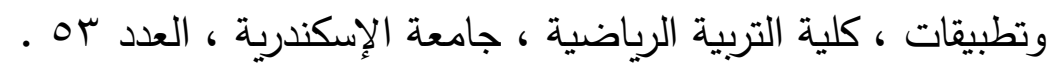

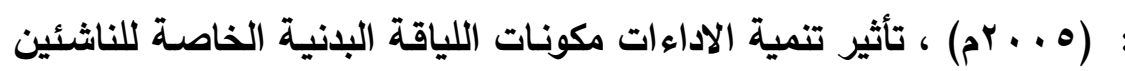

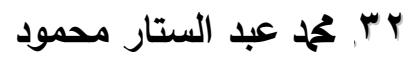
في كرة القدم ، رسـالة ماجستير غير منشـورة ، كليـة التربية الرياضسية ، جامعة المنصورة . : 99 ( (م) ، أساسيات كرة القدم ، ط ب ب، دار عالم المعرفة ، القاهرة. rr محمد عبده صـالح ، مفتـي إبراهيم حماد

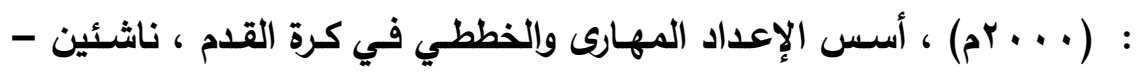
ع ب عحم ش 


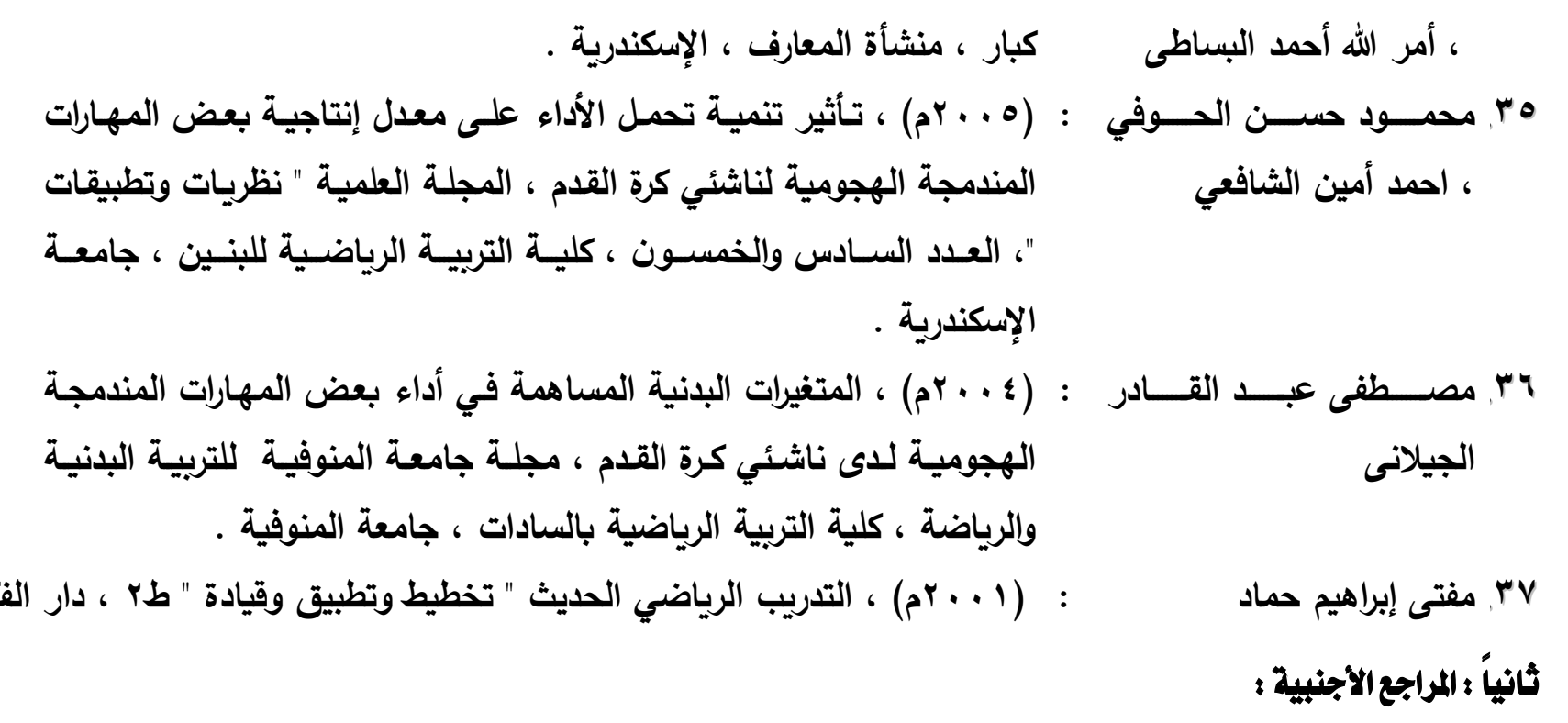

38. Asai \& carre\& : (2003) The preparation stage planning on the level of the Akatsaka\&

\&Haak skillful soccer young players, sports engineering, oxford , England . ( 4 ) - 2003, 183-192, total No . of pages : 10 .

39. Burke \& Cox \& : (2001) The effect of developing the special physical variables Mugika \& on the skillful performance of the soccer young players, tumilty journal of sports nutrition and exercise metabolism, Champaign , III , 12 ( 1 )- Mar 2001, 33-46 .

40. Dauty \& Btyand : (2002) The effect of using the precision exercises on the level \& potiron \& josse

41. Huang \& pan : (2003) The effect of the competition training on the level the skillful performance of the soccer players, journal of xi'an institute of physical education , xi'an , p . R . china , 19 (1) .

42. Kravitz, $L$ (2004) The effect of concurrent training. IDEA Personal Trainer, 15(3), 34-37.

43. Laura Hokka : (2009) serum hormone concentrations and physical performance during concurrent strength and endurance training in recreational male and female endurance runners, Master's thesis ,Science of Sport Coaching and Fitness Testing, University of Jyväskylä .

44. Leveritt, M., Abernethy, P.J., Barry, B.K. \& Logan, P.A.

(2004)Concurrent strength and endurance training. A review, Sports medicine (Auckland, N.Z.), vol. 28, no. 6, pp. 413-427.

45. Lui

: (2002) The effect of developing the mai skills on the performance level for some attaking individual playing principles for the soccer young players, journal of wuhan institute of physical education, wuhan , p . R . china, 36 ( 1 ) 
46. Patton, C. D., \& : (2005) Combining explosive and high-resistance training Hopkins, W. G. improves performance in competitive cyclists. Journal of Strength and Conditioning Research, 19(4), 826-830.

$$
\text { ثالثاً : مراجع من الثبكة الدولية للمعلومات ( انترنت) : }
$$

47- http://www.badnia.net/badnia/showthread.php?t=2951

48- http://forum.iraqacad.org/viewtopic.php? $\mathrm{f}=53 \mathrm{t} \mathrm{t}=\mathbf{2 2 8 1}$

49- http://www.sportmag.uodiyala.edu.iq/uploads/search2012/.pdf 